\title{
Drug-Eluting Balloons in the Treatment of Coronary De Novo Lesions: A Comprehensive Review
}

\author{
Rasmus Kapalu Broge Richelsen · Thure Filskov Overvad · Svend Eggert Jensen
}

Received: May 13, 2016/ Published online: July 6, 2016

(C) The Author(s) 2016. This article is published with open access at Springerlink.com

\section{ABSTRACT}

Drug-eluting balloons (DEBs) have emerged as a new application in percutaneous coronary intervention. DEBs have proven successful in the treatment of in-stent restenosis, but their role in de novo lesions is less clear. This paper provides a review of the current studies where DEBs have been used in coronary de novo lesions, either as part of a DEB-only strategy or in combination with another device, mainly a bare metal stent (BMS). By searching Pubmed

Enhanced content: To view enhanced content for this article go to http://www.medengine.com/Redeem/6ED4 F060344985C9.

Electronic supplementary material The online version of this article (doi:10.1007/s40119-016-0064-4) contains supplementary material, which is available to authorized users.

R. K. B. Richelsen $(\varangle)$ - T. F. Overvad · S. E. Jensen Department of Cardiology, Aalborg University Hospital, Aalborg, Denmark

e-mail: r.richelsen@rn.dk

T. F. Overvad

Aalborg Thrombosis Research Unit, Department of Clinical Medicine, Aalborg University, Aalborg,

Denmark

S. E. Jensen

Department of Clinical Medicine, Aalborg

University, Aalborg, Denmark and Embase we were able to identify 52 relevant studies, differing in design, intervention, and clinical setting, including patients with small vessel disease, bifurcation lesions, complex long lesions, acute myocardial infarction, diabetes mellitus, and elderly. In 23 studies, a DEB was combined with a BMS, 25 studies used a DEB-only strategy with only provisional BMS implantation, and four studies combined a DEB with a drug-eluting stent (DES). In the vast majority of studies, DEB in combination with BMS does not seem to improve clinical or angiographic outcome compared with DES, whereas a DEB-only strategy seems promising, especially when predilatation and geographical mismatch are taken into account. A lower risk of recurrent thrombosis with DEB compared with DES is not evident from the current studies. In conclusion, the main indication for DEB seems to be small vessel disease, especially in clinical scenarios in which a contraindication to dual antiplatelet therapy exists. The main approach should be a DEB-only strategy with only provisional bailout stenting, which has shown interesting results in different clinical scenarios. In general, larger randomized controlled studies with prolonged follow-up comparing DEB with 
best in class DES are warranted. Technical developments of DEBs including the use of different drugs might potentially improve the efficacy of such treatment.

Keywords: Coronary de novo lesion; Coronary naive vessel; Drug-coated balloon; Drug-eluting balloon; Paclitaxel; Paclitaxel-eluting balloon; Percutaneous coronary intervention

\section{INTRODUCTION}

Percutaneous coronary intervention (PCI) often with the implantation of a stent is considered standard revascularization treatment of flow-limiting coronary stenosis. The first introduced stent was a bare metal stent (BMS), reducing dissection, elastic recoil, and restenosis of the treated segment as compared to plain old balloon angioplasty (POBA) $[1,2]$. However, restenosis from neointimal hyperplasia in the stented area, known as in-stent restenosis, remained a complication of BMS [3]. By combining the mechanical balloon dilatation of the vessel with local delivery of antiproliferative medicine, introduction of the drug-eluting stent (DES) reduced the incidence of in-stent restenosis [4, 5]. However, DESs imply other limitations, including increased bleeding risks associated with the need for prolonged dual antiplatelet therapy (DAPT) and the risk of late and very late stent thrombosis (ST) [6-9].

Drug-eluting balloons (DEBs) have been developed in recent years to overcome some of these limitations. DEBs are semicompliant angioplasty balloons covered with an antiproliferative drug that is rapidly released upon contact with the vessel wall. Thus, mechanical expansion of the vessel is combined with release of an antiproliferative drug without leaving a foreign body. Expected potential benefits are no ST by avoiding a foreign body and less bleeding risk due to a shorter need for DAPT [10].

There is an established indication for the use of DEBs in the treatment of in-stent restenosis following implementation of a BMS or a DES [11], but the role of DEBs in the treatment of de novo lesions is less clear. The purpose of this review is to present the existing literature in which a DEB has been used alone or in combination with a stent in the treatment of coronary de novo lesions, in order to outline the potential indications, benefits, and limitations of this treatment strategy.

Pubmed, Embase, and reference lists were searched for literature up to mid April 2016, and 52 relevant studies were identified, of which three were follow-up studies and six were substudies from other trials. The treatment strategy in question is rather new, but has undergone extensive investigation within recent years, and this review provides new data compared with a previous review from 2012 [12]. This article is based on previously conducted studies and does not involve any new studies of human or animal subjects performed by any of the authors.

\section{DRUG-ELUTING BALLOONS}

Paclitaxel is at present the only drug used in DEBs for human coronary interventions. It is a lipophilic drug that readily crosses the cell membrane [13]. After cellular uptake it binds to microtubules, thereby inhibiting cell division and migration and hence proliferation of the cells [14]. Most DEBs are coated with $3 \mu \mathrm{g} / \mathrm{mm}^{2}$ paclitaxel. Usually, $60 \mathrm{~s}$ is used for balloon inflation, allowing a homogenous transfer of $8-18 \%$ of the drug to the treated vessel wall [15]. 


\begin{tabular}{|c|c|c|c|}
\hline Product name & Manufacturer & Coating & Studies \\
\hline Coroflex DEBlue* & $\begin{array}{l}\text { B. Braun Melsungen AG (Berlin, } \\
\text { Germany) }\end{array}$ & lopromide & IVUS Study [30], Clever et al. [22] \\
\hline Dior I & Eurocor (Bonn, Germany) & $\begin{array}{l}\text { Dimethyl } \\
\text { Sulfate }\end{array}$ & $\begin{array}{l}\text { PICCOLETO [48], Spanish DIOR Registry [47]***, DEBIUT } \\
\text { Registry [59], DEBIUT Trial [62] }\end{array}$ \\
\hline Dior II & Eurocor (Bonn, Germany) & Shellac & $\begin{array}{l}\text { Sgueglia et al. [61]***, Valentines II Trial [10], Spanish } \\
\text { DIOR Registry [47]***, DEB-AMI [50], DEAR [77], DEB- } \\
\text { AMI "Fourth arm" [72] }\end{array}$ \\
\hline Elutax II & $\begin{array}{l}\text { Aachen Resonance GmbH } \\
\text { (Aachen, Germany) }\end{array}$ & None & Liistro et al.[31], BELLO [49] \\
\hline Genie** $^{* *}$ & $\begin{array}{l}\text { Acrostak Corporation (Geneva, } \\
\text { Switzerland) }\end{array}$ & None & LOCAL TAX [21] \\
\hline IN.PACT Falcon & $\begin{array}{l}\text { Medtronic-Invatec (Frauenfeld, } \\
\text { Switzerland) }\end{array}$ & Urea & $\begin{array}{l}\text { Sgueglia et al. [61]***, PEGASUS [26], Basavarajaiah et al. } \\
\text { [68], Costpoulos et al. [69] }{ }^{* * *} \text {, Basavarajaiah et al. }{ }^{2}[70] \text {, } \\
\text { IN-PACT CORO [23], Kleber et al. [52] }{ }^{* * *} \text {, Schultz et al. } \\
{[63]^{* * *}}\end{array}$ \\
\hline Moxy & $\begin{array}{l}\text { Lutonix Inc. (Maple Grove, } \\
\text { Minnesota, USA) }\end{array}$ & Polysorbate & De Novo Pilot Study [32] \\
\hline Pantera Lux & $\begin{array}{l}\text { Biotronik AG (Buelach, } \\
\text { Switzerland, Germany) }\end{array}$ & $\begin{array}{l}\text { Butyryl-tri- } \\
\text { hexyl citrate }\end{array}$ & $\begin{array}{l}\text { PAPPA [71], Costopoulos et al. [69]***, DELUX Registry } \\
\text { [46], Sgueglia et al. [61]***, BIOLUX-I [65] }\end{array}$ \\
\hline SeQuent Please & $\begin{array}{l}\text { B. Braun Melsungen AG (Berlin, } \\
\text { Germany) }\end{array}$ & lopromide & $\begin{array}{l}\text { PERfECT [24], PEPCAD CTO [67], INDICOR [33], OCTOPUS } \\
\text { [28], Zurakowski et al.[27], Shin et al. [54], PEPCAD I [37], } \\
\text { SeQuent Please World Wide Registry [39], Sgueglia et al. } \\
\text { [61]***, Calé et al. [40], SeQuent Please Small Vessel } \\
\text { 'PCB only' Registry [35], Kleber et al. [52] }{ }^{* * *} \text {, The Leipzig } \\
\text { Registry [42], PEPCAD V [60], Schultz et al. [63]***, } \\
\text { BABILON [64], PEPCAD-BIF [58], PEPCAD IV DM [76], } \\
\text { Mahmood Zuhdi et al. [44], Sinaga et al. [43], Ong et al. } \\
\text { [45], Her et al. [53], Benezet et al. [41], Hee Hwa et al. } \\
\text { [73] }\end{array}$ \\
\hline
\end{tabular}

Fig. 1 Paclitaxel-coated balloons used in the treatment of coronary de novo lesions

However, the development of DEB is complex and other factors than the active drug itself contribute to the effect of DEB. The coating of the balloon is important, as the coating should be physically able to maintain the drug on the balloon during transit to the lesion, thereby reducing wash off, while at the site of dilatation it should ensure a rapid and homogenous drug transfer to the vessel wall [16]. The coating differs with the contrast agent iopromide, the film-forming agent shellac, the amphiphilic butyryl trihexyl citrate, and urea being the most widely used. DEBs with other coatings are developed, but preclinical data are limited [17]. At present, eight different CE-approved DEBs are available and seemingly no class effect exists among them [11, 14, 18].
Figure 1 shows the DEBs used in human studies in the treatment of coronary de novo lesions, SeQuent Please DEB being the most widely investigated. Zotarolimus and sirolimus DEBs have been developed and tested for use in peripheral arteries in a porcine model, but have yet to be investigated in humans $[19,20]$.

\section{Drug-Eluting Balloon in Combination with a Bare Metal Stent}

The rationale for combining the DEB with a BMS is the rapid release of the antiproliferative drug to the surface of the treated segment, while preventing acute elastic recoil by implanting a BMS. As no DES is implanted, a shorter period of DAPT is needed, thereby reducing bleeding risk. 
Clinical studies where a DEB was used in combination with a BMS are summarized in Table 1.

Several studies have showed that BMS in combination with a DEB is superior to BMS alone [21-23]. Similar results were reported with DEB in combination with an EPC stent ("endothelial progenitor cell capturing stent"). The EPC stent is covered with human CD34 antibodies that capture circulating endothelial cells and thus provides rapid endothelialization. Therefore, it cannot be considered a true BMS. However, the PERfECT stent study [24, 25] showed that DEB in combination with an EPC stent was better than EPC stent alone; however, these findings were not supported by the PEGASUS study [26]. However, when $\mathrm{DEB}+\mathrm{BMS}$ are compared to DES, at best similar results have been reported [27], but most studies have found the combination of $\mathrm{DEB}+\mathrm{BMS}$ inferior to DES. Thus, by using optical coherence tomography the OCTOPUS trial found that DEB + BMS was associated with more pronounced neointimal proliferation than DES [28, 29], while the IVUS study used intravascular ultrasound to show more pronounced neointimal hyperplasia in the $\mathrm{DEB}+\mathrm{BMS}$ group leading to more revascularizations than in the DES group [30]. The perhaps clearest signal came from the study by Liistro et al. who compared predilatation with the Elutax DEB followed by BMS implantation with the Xience DES [31]. The study planned to enroll 350 patients, but the study was prematurely halted as the combination of DEB + BMS showed non-inferiority to DES in angiographic as well as clinical endpoints, leading to five times more target lesion revascularization (TLR) in the DEB + BMS group.

A few studies have addressed the question if the sequence, DEB before or after BMS implantation, matters. Theoretically, DEB before BMS could increase the risk of geographical mismatch, i.e., the stent is implanted partly outside the DEB-treated segment. On the other hand, DEB after BMS might affect the drug delivery to the vessel as a result of interposition of stent struts [23]. However, the sequence seems to be of no clinical relevance, as several papers report similar clinical and angiographic results $[23,32,33]$. In the INDICOR study, angiographic analysis showed that most of the late lumen loss (LLL) happened at the stent edges, thus highlighting the potential pitfall of geographical mismatch [33]. The results are interesting because they open up for the opportunity of using BMS as a bailout strategy following a suboptimal result after DEB treatment [32].

In summary, the studies presented above consist of mixed populations of patients with ischemic heart disease requiring PCI at a vessel with a reference diameter of $2-3 \mathrm{~mm}$. While DEB in combination with a BMS performed better than a BMS-only strategy, the combination does not seem superior to DES in the treatment of such lesions. Furthermore, most studies compared the DEB with a paclitaxel DES, which might be misleading as sirolimus DES is considered to perform better than paclitaxel DEB [7, 34]. The sequence of DEB and BMS implantation does not seem to influence outcome as long as geographic mismatch is taken into consideration.

\section{Drug-Eluting Balloon Alone}

Several studies have focused on the use of a drug-eluting balloon alone ("DEB-only") strategy in de novo lesions. This might be accompanied by implantation of a stent only in the case of acute elastic recoil or dissection, 
Table 1 Drug-eluting balloon in combination with bare metal stent

\begin{tabular}{|c|c|c|c|c|}
\hline Study, year & $\begin{array}{l}\text { Design } \\
\text { Intervention }\end{array}$ & $\begin{array}{l}\text { Number } \\
\text { of } \\
\text { patients }\end{array}$ & $\begin{array}{l}\text { Reference mean } \\
\text { vessel diameter } \\
(\mathbf{m m})\end{array}$ & $\begin{array}{l}\text { Outcome (months of } \\
\text { follow-up) } \\
\text { Clinical } \\
\text { Angiographic }\end{array}$ \\
\hline $\begin{array}{l}\text { LOCAL-TAX [21], } \\
2009\end{array}$ & $\begin{array}{l}\text { Randomized } \\
\text { BMS + Genie DEB vs. } \\
\text { BMS vs. Taxus DES }\end{array}$ & 202 & 2.48 & $\begin{array}{l}\text { MACE, \%: } 13.4 \text { vs. } 26.8 \text { vs. } 14.9 \\
\text { (6) } \\
\text { TLR, \%: } 13.4 \text { vs. } 22.1 \text { vs. } 13.4 \text { (6) } \\
\text { In-stent LLL, mm: } 0.61 \text { vs. } 0.98 \text { vs. } \\
0.44 \text { (6) }\end{array}$ \\
\hline $\begin{array}{l}\text { PERfECT }[24,25] \\
2011 / 2016\end{array}$ & $\begin{array}{l}\text { Randomized } \\
\text { SeQuent Please } \\
\text { DEB + EPC stent vs. } \\
\text { EPC stent }\end{array}$ & 120 & 2.65 vs. 2.74 & $\begin{array}{l}\text { MACE, \%: } 4.8 \text { vs. } 17.2(6) \\
\text { TLR, \%: } 4.8 \text { vs. } 15.5(6) \\
\text { MACE, \%: } 23.5 \text { vs. } 30.4(60) \\
\text { TLR, \%: } 15 \text { vs. } 23.2(60) \\
\text { In stent LLL, mm: } 0.34 \text { vs. } 0.88 \\
\quad(6)\end{array}$ \\
\hline $\begin{array}{l}\text { De novo pilot study } \\
\text { [32], } 2011\end{array}$ & $\begin{array}{l}\text { Randomized } \\
\text { Moxy DEB + BMS vs } \\
\text { BMS + Moxy DEB }\end{array}$ & 26 & 2.81 vs. 2.41 & $\begin{array}{l}\text { MACE, \%: } 15.4 \text { vs. } 30.8(6) \\
\text { TLR, \%: } 15.4 \text { vs. } 15.4(6) \\
\text { In-stent LLL, mm: } 0.34 \text { vs. } 0.88 \\
\quad(6) \\
\text { In-stent neointimal volume } \\
\text { obstruction, \%: } 25.5 \text { vs. } 24.9(6)\end{array}$ \\
\hline $\begin{array}{l}\text { IVUS study [30], } 2012 \\
\text { (PEPCAD III } \\
\text { substudy) }\end{array}$ & $\begin{array}{l}\text { Randomized } \\
\text { Coroflex DEBlue + BMS } \\
\text { vs. Cypher DES }\end{array}$ & 55 & Not reported & $\begin{array}{l}\text { Clinical outcomes not reported } \\
\text { Stent malapposition, \%: } 6.9 \text { vs. } \\
15.4 \text { (9) } \\
\text { In-stent restenosis, \%: } 19.7 \text { vs. } 11.0 \\
\text { (9) } \\
\text { In-stent neointimal hyperplasia, } \\
\mathrm{mm}^{2}: 1.08 \text { vs. } 0.69 \text { (9) }\end{array}$ \\
\hline $\begin{array}{l}\text { PEPCAD CTO [67], } \\
2012\end{array}$ & $\begin{array}{l}\text { Observational } \\
\text { BMS + SeQuent Please } \\
\text { DEB vs. Taxus DES }\end{array}$ & 96 & $\begin{array}{l}2.98 \text { vs. } 2.95 \\
\quad \text { (post-procedure) }\end{array}$ & $\begin{array}{l}\text { MACE, \%: } 14.6 \text { vs. } 18.8 \text { (12) } \\
\text { TLR, \%: } 14.6 \text { vs. } 14.6(12) \\
\text { In-stent LLL, mm: } 0.64 \text { vs. } 0.43 \\
\quad(6)\end{array}$ \\
\hline
\end{tabular}


Table 1 continued

\begin{tabular}{|c|c|c|c|c|}
\hline Study, year & $\begin{array}{l}\text { Design } \\
\text { Intervention }\end{array}$ & $\begin{array}{l}\text { Number } \\
\text { of } \\
\text { patients }\end{array}$ & $\begin{array}{l}\text { Reference mean } \\
\text { vessel diameter } \\
(\mathbf{m m})\end{array}$ & $\begin{array}{l}\text { Outcome (months of } \\
\text { follow-up) } \\
\text { Clinical } \\
\text { Angiographic }\end{array}$ \\
\hline $\begin{array}{l}\text { Liistro et al. [31], } \\
2013\end{array}$ & $\begin{array}{l}\text { Randomized } \\
\text { Elutax DEB + BMS vs. Xience } \\
\text { DES }\end{array}$ & 125 & 2.85 vs. 2.77 & $\begin{array}{l}\text { MACE, \%: } 29 \text { vs. } 6 \text { (9) } \\
\text { TLR, \%: } 25 \text { vs. } 4 \text { (9) } \\
\text { In-stent LLL, mm: } 1.14 \text { vs. } 0.34 \\
\text { (9) } \\
\text { Binary in-stent restenosis, \%: } 17 \\
\text { vs. } 3 \text { (9) }\end{array}$ \\
\hline $\begin{array}{l}\text { INDICOR [33], } \\
2013\end{array}$ & $\begin{array}{l}\text { Randomized } \\
\text { SeQuent Please DEB + BMS } \\
\text { vs. BMS + SeQuent Please } \\
\text { DEB }\end{array}$ & 97 & 2.8 vs. 2.8 & $\begin{array}{l}\text { MACE, \%: } 16.3 \text { vs. } 8.4 \text { (12) } \\
\text { Target lesion related MACE, \%: } \\
10.2 \text { vs. } 4.2 \text { (12) } \\
\text { In-stent LLL, mm: } 0.52 \text { vs. } 0.46 \\
\text { (6) }\end{array}$ \\
\hline $\begin{array}{l}\text { PEGASUS [26], } \\
2013\end{array}$ & $\begin{array}{l}\text { Observational } \\
\text { IN.PACT Falcon DEB + EPC } \\
\text { Stent }\end{array}$ & 40 & 2.78 & $\begin{array}{l}\text { MACE, \%: 18; TLR, \%: } 10 \text { (9) } \\
\text { In-stent LLL, mm: } 0.38(6) \\
\text { Diameter stenosis, \%: } 25.3(6)\end{array}$ \\
\hline $\begin{array}{l}\text { Clever et al. [22], } \\
2014 \text { (PEPCAD } \\
\text { III substudy) }\end{array}$ & $\begin{array}{l}\text { Randomized } \\
\text { BMS vs. Coroflex DEBlue vs. } \\
\text { Cypher DES }\end{array}$ & 77 & 3.3 vs. 2.8 vs. 2.9 & $\begin{array}{l}\text { MACE, \%: } 16 \text { vs. } 0 \text { vs. } 8 \text { (9) } \\
\text { TLR, \%: } 12 \text { vs. } 0 \text { vs. } 8 \text { (9) } \\
\text { In-stent LLL, mm: } 0.85 \text { vs. } 0.36 \text { vs. } \\
0.25\end{array}$ \\
\hline $\begin{array}{l}\text { OCTOPUS [28], } \\
2014\end{array}$ & $\begin{array}{l}\text { Randomized } \\
\text { BMS + SeQuent Please DEB } \\
\text { vs. Xience V DES }\end{array}$ & 90 & 2.59 vs. 2.61 & $\begin{array}{l}\text { MACE, \%: } 9.8 \text { vs. } 10.4(6) \\
\text { TLR, \%: } 2 \text { vs. } 4.2 \text { (6) } \\
\text { In-stent LLL, mm; } 0.24 \text { vs. } 0.16 \\
\text { (6) } \\
\text { Uncovered stent struts, \%: } 5.64 \text { vs. } \\
4.93 \text { (6) }\end{array}$ \\
\hline $\begin{array}{l}\text { IN-PACT CORO } \\
\text { [23], } 2015\end{array}$ & $\begin{array}{l}\text { Randomized } \\
\text { BMS vs. IN.PACT Falcon } \\
\text { DEB + BMS vs. } \\
\text { BMS + IN.PACT Falcon } \\
\text { DEB }\end{array}$ & 30 & $\begin{array}{l}2.78 \text { vs. } 3.03 \text { vs. } \\
2.86\end{array}$ & $\begin{array}{l}\text { Both DEB groups combined: } \\
\text { MACE, \%: } 30 \text { vs. } 20 \text { (12) } \\
\text { TLR, \%: } 30 \text { vs. } 20 \text { (12) } \\
\text { In-stent LLL, mm: } 0.85 \text { vs. } 0.50 \text { vs. } \\
0.64 \text { (6) } \\
\text { Mean neointimal area, } \mathrm{mm}^{2}: 3.03 \\
\text { vs. } 1.96 \text { vs. } 2.06 \text { (6) } \\
\text { Area obstruction, \%: } 37.5 \text { vs. } 19.5 \\
\text { vs. } 29.1 \text { (6) }\end{array}$ \\
\hline
\end{tabular}


Table 1 continued

\begin{tabular}{|c|c|c|c|c|}
\hline Study, year & $\begin{array}{l}\text { Design } \\
\text { Intervention }\end{array}$ & $\begin{array}{l}\text { Number } \\
\text { of patients }\end{array}$ & $\begin{array}{l}\text { Reference mean } \\
\text { vessel diameter } \\
(\mathrm{mm})\end{array}$ & $\begin{array}{l}\text { Outcome (months of } \\
\text { follow-up) } \\
\text { Clinical } \\
\text { Angiographic }\end{array}$ \\
\hline $\begin{array}{l}\text { Żurakowski } \\
\text { et al. [27], } \\
2015\end{array}$ & $\begin{array}{l}\text { Randomized } \\
\text { BMS + SeQuent Please DEB } \\
\text { vs. Coroflex Please DES }\end{array}$ & 202 & 2.52 vs. 2.62 & $\begin{array}{l}\text { MACE, \%: } 7.0 \text { vs. } 6.9(9) \\
\text { TLR, \%: } 6.9 \text { vs. } 5.0(9) \\
\text { In-stent, LLL, mm: } 0.21 \text { vs. } 0.30 \\
\text { (9) }\end{array}$ \\
\hline $\begin{array}{l}\text { Otto et al. [29], } \\
2016 \\
\text { (substudy [28]) }\end{array}$ & $\begin{array}{l}\text { Observational } \\
\text { BMS + SeQuent Please DEB }\end{array}$ & 21 & Not reported & $\begin{array}{l}\text { Incomplete stent strut apposition, } \\
\%: 11.4 \text { at } 2 \text { months and } 1.8 \text { at } \\
6 \text { months } \\
\text { Uncovered stent struts, \%: } 14.5 \text { at } \\
2 \text { months and } 2.0 \text { at } 6 \text { months } \\
\text { Positive vessel remodelling } \\
4.9 \text { at } 2 \text { months and } 2.0 \text { at } \\
6 \text { months }\end{array}$ \\
\hline
\end{tabular}

$L L L$ late lumen loss-reflects the loss of lumen in the treated segment usually measured by subtracting the lumen diameter at follow-up from the lumen diameter just after the PCI procedure; $M A C E$ major adverse cardiac event-not consistently defined among the different studies, but most frequently including the combination of either death, myocardial infarct, target lesion revascularization, or target vessel revascularization; TLR target lesion revascularization-revascularization within the treated/stented area, usually including $5 \mathrm{~mm}$ of the proximal and distal segment adjacent to the treated/stented area

so-called bailout stenting, see Table 2 . The studies presented have mainly focused on small vessel de novo lesions. No clear definition of small vessel in terms of the reference vessel diameter exists, but a vessel diameter less than $2.8 \mathrm{~mm}$ is often regarded a small vessel [35]. The absolute LLL is similar and independent of vessel diameter; and since small vessels have less room to accommodate neointimal tissue growth, restenosis of small vessels has remained a challenge even in the DES era [36]. Hence, it would be promising to totally avoid a stent implantation in such lesions. Studies using a DEB-only strategy in specific clinical scenarios other than small vessel disease are presented later.
The first study using a DEB-only strategy in de novo lesions was the PEPCAD I (Paclitaxel-Eluting PTCA-Balloon Catheter to Treat Small Vessel Coronary Artery Disease) study [37]. A SeQuent Please DEB was used for dilatation, and the proportion of patients requiring additional BMS deployment was 27\%. An intention-to-treat analysis showed MACE at $15.3 \%$ after 12 months. However, a per-protocol analysis indicated significantly different outcomes both clinically and angiographically in favor of the DEB-only strategy, with TLR of $5 \%$ in the DEB-only group and $28 \%$ in the DEB + BMS group. This difference was likely explained by geographical mismatch, i.e., the BMS was partly deployed 
Table 2 Drug-eluting balloon alone

\begin{tabular}{|c|c|c|c|c|c|}
\hline Study, year & $\begin{array}{l}\text { Design } \\
\text { Intervention }\end{array}$ & $\begin{array}{l}\text { Number } \\
\text { of } \\
\text { patients }\end{array}$ & $\begin{array}{l}\text { Reference mean } \\
\text { vessel diameter } \\
(\mathrm{mm})\end{array}$ & $\begin{array}{l}\text { Bailout } \\
(\%)\end{array}$ & $\begin{array}{l}\text { Outcome (months of } \\
\text { follow-up) } \\
\text { Clinical } \\
\text { Angiographic }\end{array}$ \\
\hline $\begin{array}{l}\text { PEPCAD I }[37,38] \\
2010 / 2013\end{array}$ & $\begin{array}{l}\text { Observational } \\
\text { SeQuent Please DEB }\end{array}$ & 118 & 2.35 & 27 & $\begin{array}{l}\text { Intention to treat } \\
\text { MACE, \%: } 15.3 \text { (12, } \\
\text { 36), TLR, \%: } 11.9 \\
(12,36) \\
\text { Among patients with } \\
\text { no bailout } \\
\text { MACE, \%: 6.1 (12, } \\
\text { 36) } \\
\text { TLR, \%: } 4.9(12,36) \\
\text { In-segment LLL, mm: } \\
0.28 \text { (12) }\end{array}$ \\
\hline $\begin{array}{l}\text { PICCOLETO [48], } \\
2010\end{array}$ & $\begin{array}{l}\text { Randomized } \\
\text { DIOR DEB vs. Taxus } \\
\text { Liberté DES }\end{array}$ & 60 & 2.45 vs. 2.36 & 36 & $\begin{array}{l}\text { MACE, \%: } 35.7 \text { vs. } \\
13.8 \text { (9) } \\
\text { TLR, \%: } 32.1 \text { vs. } 10.3 \\
\text { (9) } \\
\text { Diameter stenosis, \%: } \\
43.6 \text { vs. } 24.3(6)\end{array}$ \\
\hline $\begin{array}{l}\text { SeQuent Please World } \\
\text { Wide Registry [39], } \\
2012\end{array}$ & $\begin{array}{l}\text { Observational } \\
\text { SeQuent Please DEB } \\
\text { SeQuent Please } \\
\text { DEB + BMS }\end{array}$ & 101 & 2.8 & $\begin{array}{l}0^{\mathrm{a}} \\
100\end{array}$ & $\begin{array}{l}\text { MACE, \%: } 2.6(9) \\
\text { TLR, \%: } 1.0(9) \\
\text { MACE, \%: } 2.4(9) \\
\text { TLR, \%: } 2.4(9)\end{array}$ \\
\hline $\begin{array}{l}\text { BELLO }[49,51], \\
2012 / 2015\end{array}$ & $\begin{array}{l}\text { Randomized } \\
\text { IN.PACT Falcon DEB } \\
\text { vs. Taxus Liberté DES }\end{array}$ & 182 & 2.15 vs. 2.25 & 20 & $\begin{array}{l}\text { MACE, \%: } 10 \text { vs. } 16.3 \\
(6) \\
\text { and } 14.8 \text { vs. } 25.3(24) \\
\text { TLR, \%: } 4.4 \text { vs. } 7.6(6) \\
\text { and } 6.8 \text { vs. } 12.1(24) \\
\text { In-balloon (in-stent) } \\
\text { LLL, mm: } 0.08 \text { vs. } \\
0.29 \text { (6) }\end{array}$ \\
\hline $\begin{array}{l}\text { Valentines II trial [10], } \\
2013\end{array}$ & $\begin{array}{l}\text { Observational } \\
\text { DIOR II DEB }\end{array}$ & 103 & 2.40 & 11.9 & $\begin{array}{l}\text { MACE, \%: } 8.7(7.5) \\
\text { TLR, \%: } 2.9(7.5) \\
\text { In-balloon LLL, mm: } \\
0.38(7.5)\end{array}$ \\
\hline
\end{tabular}


Table 2 continued

\begin{tabular}{|c|c|c|c|c|c|}
\hline Study, year & $\begin{array}{l}\text { Design } \\
\text { Intervention }\end{array}$ & $\begin{array}{l}\text { Number } \\
\text { of } \\
\text { patients }\end{array}$ & $\begin{array}{l}\text { Reference mean } \\
\text { vessel diameter } \\
(\mathbf{m m})\end{array}$ & $\begin{array}{l}\text { Bailout } \\
\text { (\%) }\end{array}$ & $\begin{array}{l}\text { Outcome (months of } \\
\text { follow-up) } \\
\text { Clinical } \\
\text { Angiographic }\end{array}$ \\
\hline Calé et al. [40], & Observational & 74 & Not reported & 3 & MACE, \%: 14.7 (12) \\
\hline 2013 & SeQuent Please DEB & & & & TLR, \%: $6.2(12)$ \\
\hline \multirow{2}{*}{$\begin{array}{l}\text { SeQuent Please Small } \\
\text { Vessel "PCB Only" } \\
\text { Registry [35], } 2014\end{array}$} & Observational & 447 & 2.14 & 6 & MACE, \%: 4.7 (9) \\
\hline & SeQuent Please DEB & & & & TLR, \%: 3.6 (9) \\
\hline \multirow{2}{*}{$\begin{array}{l}\text { DELUX Registry [46], } \\
2015\end{array}$} & Observational & \multirow[t]{2}{*}{105} & \multirow{2}{*}{$\begin{array}{l}\text { Not reported } \\
\qquad(69.4 \%<2.75)\end{array}$} & \multirow[t]{2}{*}{22.5} & MACE, \%: 9.4 (12) \\
\hline & Pantera Lux DEB & & & & TLR, \%: 3.1 (12) \\
\hline \multirow[t]{4}{*}{ Kleber et al. [52], 2015} & $\begin{array}{l}\text { Observational } \\
\text { SeQuent Please DEB/ }\end{array}$ & \multirow[t]{4}{*}{56} & \multirow[t]{4}{*}{2.59} & \multirow[t]{4}{*}{$0^{\mathrm{a}}$} & $\begin{array}{l}\text { MACE, \%: } 1.8 \text {, TLR, } \\
\%: 0(4)\end{array}$ \\
\hline & \multirow{3}{*}{$\begin{array}{l}\text { SeQuent Please DEB/ } \\
\text { IN.PACT Falcon DEB } \\
\text { (pre- vs. post-intervention) }\end{array}$} & & & & Minimal lumen \\
\hline & & & & & $\begin{array}{l}\text { diameter in-lesion, } \\
\mathrm{mm}: 0.81 \text { vs. } 1.75 .(4)\end{array}$ \\
\hline & & & & & $\begin{array}{l}\text { Diameter stenosis } \\
\text { in-lesion, \%: } 69.2 \text { vs. } \\
33.8 \text { (4) }\end{array}$ \\
\hline \multirow{3}{*}{$\begin{array}{l}\text { Spanish DIOR Registry } \\
\text { [47], } 2015\end{array}$} & Observational & \multirow[t]{3}{*}{104} & \multirow[t]{3}{*}{1.95} & \multirow[t]{3}{*}{6.8} & MACE, \%: 4.8 (12) \\
\hline & \multirow[t]{2}{*}{ DIOR I/DIOR II DEB } & & & & TLR, \%: 2.9 (12) \\
\hline & & & & & LLL, mm: 0.31 (7.5) \\
\hline \multirow[t]{3}{*}{ Shin et al. [54], 2015} & Observational & 66 & 2.69 vs. 2.92 & & MACE, \%: 0 vs. 9.1 (9) \\
\hline & \multirow{2}{*}{$\begin{array}{l}\text { SeQuent Please DEB vs. } \\
\text { DES }\end{array}$} & & & & TLR, \%: 0 vs. 4.5 (9) \\
\hline & & & & & $\begin{array}{l}\text { In-lesion/stent LLL, } \\
\text { mm: } 0.05 \text { vs. } 0.40(9)\end{array}$ \\
\hline \multirow{4}{*}{$\begin{array}{l}\text { Leipzig Registry [42], } \\
2016\end{array}$} & \multirow{4}{*}{$\begin{array}{l}\text { Observational } \\
\text { SeQuent Please DEB }\end{array}$} & \multirow[t]{4}{*}{76} & \multirow[t]{4}{*}{ Not reported } & \multirow[t]{4}{*}{26.3} & Myocardial infarction, \\
\hline & & & & & \%: $3.9(27)$ \\
\hline & & & & & $\begin{array}{l}\text { All-cause mortality, \%: } \\
9.2(27)\end{array}$ \\
\hline & & & & & TLR, \%: 0 (27) \\
\hline \multirow[t]{2}{*}{ Her et al. [53], 2016} & Observational & 72 & 2.3 vs. 2.1 & $0^{\mathrm{a}}$ & TLR, \%: 0 vs. 4.3 (9) \\
\hline & $\begin{array}{l}\text { SeQuent Please DEB vs. } \\
\text { POBA }\end{array}$ & & & & \\
\hline \multirow{2}{*}{$\begin{array}{l}\text { Benezet et al. [41], } \\
2016\end{array}$} & Observational & \multirow[t]{2}{*}{53} & \multirow[t]{2}{*}{2.4} & \multirow[t]{2}{*}{25} & MACE, \%: 8.9 (36) \\
\hline & SeQuent Please DEB & & & & TLR, \%: 5.4 (36) \\
\hline
\end{tabular}


Table 2 continued

\begin{tabular}{|c|c|c|c|c|c|}
\hline Study, year & $\begin{array}{l}\text { Design } \\
\text { Intervention }\end{array}$ & $\begin{array}{l}\text { Number } \\
\text { of } \\
\text { patients }\end{array}$ & $\begin{array}{l}\text { Reference mean } \\
\text { vessel diameter } \\
(\mathrm{mm})\end{array}$ & Bailout (\%) & $\begin{array}{l}\text { Outcome (months of } \\
\text { follow-up) } \\
\text { Clinical } \\
\text { Angiographic }\end{array}$ \\
\hline \multirow[t]{3}{*}{ Ann et al. [55], 2016} & Observational & 27 & 2.53 & $0^{\mathrm{a}}$ & MACE, \%: 3.7 (9) \\
\hline & SeQuent Please DEB & & & & TLR, \%: 0 (9) \\
\hline & & & & & $\begin{array}{l}\text { In-lesion LLL, mm: } \\
0.02 \mathrm{~mm} \text { (9) }\end{array}$ \\
\hline
\end{tabular}

See Table 1 for abbreviations

a By design no stent implanted

outside the DEB-treated area, highlighting this potential pitfall. Thus, in patients with restenosis following bailout BMS, geographical mismatch was seen in $77 \%$ of patients versus $19 \%$ among the group without restenosis, but this could also be explained by the need for implantation of a BMS in more complex lesions. After a 3-year follow-up period, no additional major coronary events were observed in either group, suggesting that after the first 6 months, lesions are relatively stable [38].

The SeQuent Please World Wide Registry was a large multicenter observational study assessing the safety and efficacy of the SeQuent Please DEB [39]. Across 75 centers, 2095 patients were included. In the subset of 572 patients with de novo stenosis, 491 patients were treated with DEB alone and 101 patients with DEB + BMS (either planned or as part of bailout stenting). Low and comparable rates of TLR and MACE were reported in both groups, markedly lower than observed in previous studies.

Other smaller real-world registries have been performed assessing the SeQuent Please DEB using an all-comer inclusion strategy. In a multicenter registry of 156 patients treated with SeQuent Please DEB, 74 patients had treatment of de novo lesions [40]. A very low bailout frequency was reported, but clinical outcome was worse than in other registries and clinical trials. The authors speculated that this was due to a high-risk population [40]. A long-term follow-up registry was performed by Benezet et al., showing persistently low MACE and TLR rates after 36 months and no occurrence of vessel/stent thrombosis [41]. Twenty-five percent received bailout BMS implantation which was not associated with a less favorable outcome (MACE 7.1\% with additional BMS and 9.5\% without BMS) [41]. The prospective Leipzig Registry evaluated the clinical outcome in 484 patients treated with a SeQuent Please DEB [42]. De novo vessel disease was seen in 76 patients (15.7\%). In de novo lesions, no TLR was seen after 27 months. MACE was defined differently than in other studies and was thus difficult to compare [42]. Being the second largest real world registry, the SeQuent Please Small Vessel "PCB Only" Registry was a prospective multicenter study assessing the safety and efficacy of the SeQuent Please DEB in 447 patients [35]. A low bailout proportion was reported, as were low TLR and MACE rates, and additional stenting was only associated with marginally higher TLR rates $3.6 \%$ in the DEB-only vs. $4 \%$ in the DEB + BMS group). 
Compared to the SeQuent Please World Wide Registry [39], the slightly higher clinical event rates seen in the SeQuent Please Small Vessel "PCB Only" Registry are probably explained by the smaller reference vessel diameter in this study, as also suggested by the authors [35]. From the SeQuent Please Small Vessel "РCB Only" Registry, three substudies have been reported focusing on the DEB-only strategy for elderly patients ( $\geq 75$ years) [43], patients with acute coronary syndrome [44], and Asian vs. Western patients [45]. These studies are presented in Table 3. Interestingly, despite more comorbidities in the elderly population and significantly smaller vessels and longer lesions among Asian patients, almost similar bailout rates and clinical outcomes are reported among the groups. This was true for patients presenting with acute coronary syndrome (STEMI or non-STEMI) as well as for patients with non-acute coronary syndrome.

Other DEBs than the SeQuent Please DEB have been assessed in real-world registries. The DELUX registry was a real-world registry assessing safety and efficacy of the Pantera Lux DEB [46]. De novo lesions were present in 105 patients, and after 12 months MACE and TLR rates were comparable with rates from real-world registries using SeQuent Please. Bailout stenting was performed in $22.5 \%$ of patients and associated with a twofold clinical event rate [46]. The Spanish DIOR Registry was another observational real-world multicenter study reporting on outcomes following implantation of DIOR I or II DEB [47]. A total of 104 patients were included. Bailout proportions were low and so was the rate of MACE and TLR at 12 months. Only half of the patients underwent angiographic follow-up, revealing an LLL of $0.31 \mathrm{~mm}$. As seen in other studies, bailout BMS implantation predicted both MACE and TLR [47].

The PICCOLETO trial was the first randomized study comparing a Dior I DEB with a Taxus Liberté DES in small vessel disease [48]. The study was interrupted after enrollment of two-thirds of patients because of superiority in favor of the DES group. The primary endpoint was percentage diameter stenosis in-segment/ in-balloon, and stenosis rates were significantly lower in the DES group; there was also a strong trend toward better clinical outcome with tree times as many MACE in the DEB group than in the DES group, mainly driven by a difference in TLR events [48].

The Balloon Elution and Late Loss Optimization (BELLO) trial was the second randomized study comparing a DEB with DES in small vessel de novo lesions [49], and the IN.PACT Falcon DEB was compared with the Taxus Liberté DES in a sample of 182 patients. The primary endpoint of in-balloon (in-stent) LLL was significantly less frequent in DEB compared with DES. The clinical event rate in the DES group was comparable to the rate observed in the DES group from the PICCOLETO study [48]. In contrast, the DEB group in the BELLO study experienced clinical outcomes equal to the extent observed in the DES group. The diverging results from BELLO and PICCOLETO might be due to several factors. While the same DES was used in the two studies, the PICCOLETO study used a first-generation DEB, whereas the BELLO study used a second-generation DEB. Predilatation before DEB treatment was done in only $25 \%$ of patients in PICCOLETO vs. $96.8 \%$ in the BELLO study. Predilatation is thought to improve drug uptake by creating microdissections in the vessel wall and thus facilitating drug transport through the intima and media layers [50]. In case of bailout BMS 
Table 3 Drug-eluting balloons in specific clinical scenarios

\begin{tabular}{|c|c|c|c|c|}
\hline Study, year & $\begin{array}{l}\text { Design } \\
\text { Intervention }\end{array}$ & $\begin{array}{l}\text { Number } \\
\text { of } \\
\text { patients }\end{array}$ & $\begin{array}{l}\text { Mean vessel } \\
\text { diameter }(\mathbf{m m})\end{array}$ & $\begin{array}{l}\text { Outcome (months of } \\
\text { follow-up) } \\
\text { Clinical } \\
\text { Angiographic }\end{array}$ \\
\hline \multicolumn{5}{|l|}{ Bifurcations } \\
\hline $\begin{array}{l}\text { DEBIUT Registry [59], } \\
2008\end{array}$ & $\begin{array}{l}\text { Observational } \\
\mathrm{DEB} \text { in } \mathrm{MB} \text { and } \mathrm{SB}+\mathrm{BMS} \text { in } \mathrm{MB}\end{array}$ & 20 & $\begin{array}{l}\text { MB: } 3.0 \\
\text { SB: } 2.4\end{array}$ & $\begin{array}{l}\text { MACE, \%: } 0 \\
\text { TLR, \%: } 0\end{array}$ \\
\hline PEPCAD-V [60], 2011 & $\begin{array}{l}\text { Observational } \\
\mathrm{DEB} \text { in } \mathrm{MB} \text { and } \mathrm{SB}+\mathrm{BMS} \text { in } \mathrm{MB}\end{array}$ & 28 & Not reported & $\begin{array}{l}\text { MACE, \%: } 10.7 \\
\text { TLR, \%: } 3.8 \text { (9) } \\
\text { In lesion LLL, mm: } \\
\text { MB 0.38, SB } 0.2(9)\end{array}$ \\
\hline Sgueglia et al. [61], 2011 & $\begin{array}{l}\text { Observational } \\
\mathrm{BMS}+\text { “various” DEB }\end{array}$ & 14 & $\begin{array}{l}\text { MB: } 3.3 \\
\text { SB: } 2.5\end{array}$ & MACE, \%: 0 (8) \\
\hline DEBIUT [62], 2012 & $\begin{array}{l}\text { Randomized } \\
\mathrm{DEB} \text { in } \mathrm{MB} \text { and } \mathrm{SB}+\mathrm{BMS} \text { in } \mathrm{MB} \\
\text { vs. BMS in } \mathrm{MB} \text { vs. DES in } \mathrm{MB}\end{array}$ & 117 & $\begin{array}{l}\text { Proximal MB: } \\
1.30 \text { vs. } 1.24 \text { vs. } \\
1.40 \\
\text { Distal MB: } 1.15 \\
\text { vs. } 1.06 \text { vs. } 1.06 \\
\text { SB: } 1.17 \text { vs. } 1.15 \\
\text { vs. } 1.23\end{array}$ & $\begin{array}{l}\text { MACE, \%: } 20 \text { vs. } 29.7 \\
\text { vs. } 17.5 \text { (12) } \\
\text { TLR, \%: } 15 \text { vs. } 27 \text { vs. } \\
15 \text { (12) } \\
\text { LLL in SB, mm: } 0.19 \\
\text { vs. } 0.21 \text { vs. } 0.11 \text { (6) }\end{array}$ \\
\hline Schulz et al. [63], 2014 & $\begin{array}{l}\text { Observational } \\
\mathrm{DEB} \text { in } \mathrm{MB} \text { and } \mathrm{SB}\end{array}$ & 39 & Not reported & $\begin{array}{l}\text { MACE, \%: } 7.7(4) \\
\text { TLR, \%: } 7.7(4)\end{array}$ \\
\hline BABILON [64], 2014 & $\begin{array}{l}\text { Randomized } \\
\mathrm{DEB} \text { in } \mathrm{MB} \text { and } \mathrm{SB}+\mathrm{BMS} \text { in } \mathrm{MB} \\
\text { vs } \\
\text { DES in } \mathrm{MB}\end{array}$ & 108 & $\begin{array}{l}\text { MB: } 3.11 \text { vs. } 3.02 \\
\text { SB: } 2.29 \text { vs. } 2.35\end{array}$ & $\begin{array}{l}\text { MACE, \%: } 17.3 \text { vs. } \\
12.5(24) \\
\text { TLR, \%: } 15.4 \text { vs. } 3.6 \\
(24) \\
\text { In-segment LLL, mm } \\
\text { MB: } 0.31 \text { vs. } 0.16(9) \\
\text { SB: }-0.04 \text { vs. }-0.03 \\
\text { (9) }\end{array}$ \\
\hline $\begin{array}{l}\text { BIOLUX-I study [65], } \\
2015\end{array}$ & $\begin{array}{l}\text { Observational } \\
\mathrm{DES} \text { in } \mathrm{MB}+\mathrm{DEB} \text { in } \mathrm{SB}\end{array}$ & 35 & $\begin{array}{l}\text { MB: } 2.65 \\
\text { SB: } 2.01\end{array}$ & $\begin{array}{l}\text { MACE, \%: } 5.7(12) \\
\text { TLR, \%: } 2.9(12) \\
\text { SB LLL, mm: } 0.10(9)\end{array}$ \\
\hline
\end{tabular}


Table 3 continued

\begin{tabular}{|c|c|c|c|c|}
\hline Study, year & $\begin{array}{l}\text { Design } \\
\text { Intervention }\end{array}$ & $\begin{array}{l}\text { Number } \\
\text { of } \\
\text { patients }\end{array}$ & $\begin{array}{l}\text { Mean vessel } \\
\text { diameter }(\mathrm{mm})\end{array}$ & $\begin{array}{l}\text { Outcome (months of } \\
\text { follow-up) } \\
\text { Clinical } \\
\text { Angiographic }\end{array}$ \\
\hline $\begin{array}{l}\text { PEPCAD-BiF [58], } \\
2016\end{array}$ & $\begin{array}{l}\text { Randomized } \\
\text { DEB vs. plain old balloon } \\
\text { angioplasty }\end{array}$ & 64 & 2.40 vs. 2.37 & $\begin{array}{l}\text { MACE, \%: not } \\
\text { reported } \\
\text { TLR, \%: } 3.1 \text { vs. } 9.4 \\
\text { (9) } \\
\text { In-lesion LLL, mm: } \\
0.13 \text { vs. } 0.51 \text { (9) }\end{array}$ \\
\hline Chronic total occlusion or & diffuse long lesions & & & \\
\hline $\begin{array}{l}\text { PEPCAD CTO [67], } \\
2012\end{array}$ & $\begin{array}{l}\text { Randomized } \\
\text { BMS + SeQuent Please DEB vs. } \\
\text { Taxus DES }\end{array}$ & 48 & $\begin{array}{l}2.98 \text { vs. } 2.95 \\
\quad \text { (post-procedure) } \\
\text { Length, } \mathrm{mm}: 59.7 \\
\text { vs. } 56.2\end{array}$ & $\begin{array}{l}\text { MACE, \%: } 14.6 \text { vs. } \\
18.8 \text { (12) } \\
\text { TLR, \%: } 14.6 \text { vs. } 14.6 \\
(12) \\
\text { In-stent LLL, mm: } \\
0.64 \text { vs. } 0.43(6)\end{array}$ \\
\hline $\begin{array}{l}\text { Basavarajaiah et al. [68], } \\
2013\end{array}$ & $\begin{array}{l}\text { Observational } \\
\text { IN.PACT Falcon DEB + “various” } \\
\text { DES }\end{array}$ & 20 & $\begin{array}{l}\text { Not reported for } \\
\text { specific } \\
\text { subgroups } \\
\text { Length, mm: } 97 \% \\
\text { of lesions } \geq 30\end{array}$ & $\begin{array}{l}\text { MACE, \%: } 5 \text { (13) } \\
\text { TLR, \%: } 4.3 \text { (13) }\end{array}$ \\
\hline $\begin{array}{l}\text { Costopoulos et al. [69], } \\
2013\end{array}$ & $\begin{array}{l}\text { Observational } \\
\text { IN.PACT Falcon/Pantera Lux } \\
\text { DEB } \pm \text { “various” DES vs. "various" } \\
\text { DES }\end{array}$ & 69 vs. 93 & $\begin{array}{l}2.44 \text { vs. } 2.58 \\
\text { Length, } \mathrm{mm}: 47.3 \\
\text { vs. } 47.6\end{array}$ & $\begin{array}{l}\text { MACE, \%: } 18.8 \text { vs. } \\
24.7(26) \\
\text { TLR, \%: } 7.2 \text { vs. } 10.8 \\
(26)\end{array}$ \\
\hline $\begin{array}{l}\text { Basavarajaiah et al. [70], } \\
2014\end{array}$ & $\begin{array}{l}\text { Observational } \\
\text { IN.PACT Falcon DEB (DES } \\
\text { bailout in 22\%) }\end{array}$ & 79 & $\begin{array}{l}2.66 \text { (DEB } \\
\text { diameter) } \\
\text { Length, mm: } 31.2 \\
\text { (DEB length) }\end{array}$ & $\begin{array}{l}\text { MACE, \%: } 16.5(15) \\
\text { TLR, \%: } 17.7(15)\end{array}$ \\
\hline \multicolumn{5}{|l|}{ Myocardial infarction } \\
\hline DEB-AMI [50], 2012 & $\begin{array}{l}\text { Randomized } \\
\text { BMS vs. DIOR II DEB + BMS vs. } \\
\text { Taxus DES }\end{array}$ & 150 & $\begin{array}{l}2.84 \text { vs. } 2.84 \text { vs. } \\
2.78\end{array}$ & $\begin{array}{l}\text { MACE, \%: } 23.5 \text { vs. } 20 \\
\text { vs. } 4 \text { (6) } \\
\text { TLR, \%: } 17.6 \text { vs. } 20 \\
\text { vs. } 2.1 \text { (6) } \\
\text { In-stent LLL, } \mathrm{mm} \text { : } \\
0.74 \text { vs. } 0.64 \text { vs. } 0.21 \\
\text { (6) }\end{array}$ \\
\hline
\end{tabular}


Table 3 continued

\begin{tabular}{|c|c|c|c|c|}
\hline Study, year & $\begin{array}{l}\text { Design } \\
\text { Intervention }\end{array}$ & $\begin{array}{l}\text { Number } \\
\text { of } \\
\text { patients }\end{array}$ & $\begin{array}{l}\text { Mean vessel } \\
\text { diameter }(\mathrm{mm})\end{array}$ & $\begin{array}{l}\text { Outcome (months of } \\
\text { follow-up) } \\
\text { Clinical } \\
\text { Angiographic }\end{array}$ \\
\hline PAPPA [71], & Observational & 100 & 3.02 & MACE, \%: 5 \\
\hline 2014 & Pantera Lux DEB & & & TLR, \%: 3 \\
\hline $\begin{array}{l}\text { DEB-AMI “Fourth arm” } \\
\text { [72], } 2015\end{array}$ & $\begin{array}{l}\text { Observational } \\
\text { DIOR II DEB }\end{array}$ & 40 & 2.83 & $\begin{array}{l}\text { MACE, \%: } 17.5(6) \\
\text { TLR, \%: } 12.5(6) \\
\text { In-balloon LLL, mm: } \\
0.51(6)\end{array}$ \\
\hline Ho et al. [73], 2015 & $\begin{array}{l}\text { Observational } \\
\text { SeQuent Please DEB }\end{array}$ & 89 & 2.4 & $\begin{array}{l}\text { MACE, \%: } 3(1) \\
\text { TLR, \%: } 0 \text { (1) }\end{array}$ \\
\hline $\begin{array}{l}\text { Mahmood Zuhdi et al. } \\
\text { [44], } 2016 \text { (substudy } \\
{[35] \text { ) }}\end{array}$ & $\begin{array}{l}\text { Observational } \\
\text { SeQuent Please DEB } \\
\text { ACS } \\
\text { No ACS }\end{array}$ & $\begin{array}{l}447 \\
113 \\
334\end{array}$ & $\begin{array}{l}2.15 \\
2.14\end{array}$ & $\begin{array}{l}\text { MACE, \%: 3.6; TLR, } \\
\text { \%: } 1.2 \text { (9) } \\
\text { MACE, \%: 5.0; TLR, } \\
\text { \%: } 4.3 \text { (9) }\end{array}$ \\
\hline Patients with diabetes & & & & \\
\hline $\begin{array}{l}\text { PEPCAD IV DM [76], } \\
2011\end{array}$ & $\begin{array}{l}\text { Randomized } \\
\text { SeQuent Please DEB + BMS vs. } \\
\text { Taxus Liberté DES }\end{array}$ & 84 & 2.78 vs. 2.75 & $\begin{array}{l}\text { MACE, \%: } 13.3 \text { vs. } \\
15.4 \text { (9) } \\
\text { TLR, \%: } 8.9 \text { vs. } 10.3 \\
\text { (9) } \\
\text { In-stent LLL, mm: } \\
0.51 \text { vs. } 0.53 \text { (9) }\end{array}$ \\
\hline DEAR [77], 2012 & $\begin{array}{l}\text { Observational } \\
\text { DIOR II DEB + BMS vs. BMS vs. } \\
\text { “various” DES }\end{array}$ & $\begin{array}{r}92 \text { vs. } 96 \\
\text { vs. } 129\end{array}$ & Not reported & $\begin{array}{l}\text { MACE, \%: } 13.2 \text { vs. } \\
32.2 \text { vs. } 18.6 \text { (12) } \\
\text { TLR, \%: } 6.6 \text { vs. } 21 \text { vs. } \\
9.4 \text { (12) }\end{array}$ \\
\hline Elderly patients & & & & \\
\hline $\begin{array}{l}\text { Sinaga et al. [43], } 2015 \\
\text { (substudy [35]) }\end{array}$ & $\begin{array}{l}\text { Observational } \\
\text { SeQuent Please DEB } \\
\text { Age }<75 \\
\text { Age } \geq 75\end{array}$ & $\begin{array}{l}447 \\
334\end{array}$ & $\begin{array}{l}2.14 \\
2.18\end{array}$ & $\begin{array}{l}\text { MACE, \%: 4.2; TLR, } \\
\text { \% } 3.9 \text { (9) } \\
\text { MACE, \%: 6.1; TLR, } \\
\text { \%: } 3.0 \text { (9) }\end{array}$ \\
\hline
\end{tabular}


Table 3 continued

\begin{tabular}{|c|c|c|c|c|}
\hline Study, year & $\begin{array}{l}\text { Design } \\
\text { Intervention }\end{array}$ & $\begin{array}{l}\text { Number } \\
\text { of } \\
\text { patients }\end{array}$ & $\begin{array}{l}\text { Mean vessel } \\
\text { diameter }(\mathbf{m m})\end{array}$ & $\begin{array}{l}\text { Outcome (months of } \\
\text { follow-up) } \\
\text { Clinical } \\
\text { Angiographic }\end{array}$ \\
\hline \multicolumn{5}{|c|}{ Asian vs. Western patients } \\
\hline \multirow[t]{2}{*}{$\begin{array}{l}\text { Ong et al. [45], } 2014 \\
\text { (substudy [35]) }\end{array}$} & $\begin{array}{l}\text { Observational } \\
\text { SeQuent Please DEB }\end{array}$ & 447 & $\begin{array}{l}2.03 \\
2.17\end{array}$ & \multirow{2}{*}{$\begin{array}{l}\text { MACE, \%: 2.7; TLR, } \\
\% 1.4(9) \\
\text { MACE, \%: 5.1; TLR, } \\
\%: 4.2(9)\end{array}$} \\
\hline & $\begin{array}{l}\text { Asian patients } \\
\text { Western patients }\end{array}$ & 374 & & \\
\hline
\end{tabular}

$M B$ main branch, $S B$ side branch. For other abbreviations, see Table 1

implantation, investigators in the BELLO study were careful with placing the BMS within the DEB treated area, thereby avoiding geographical mismatch, which was not taken into consideration in the PICCOLETO study. The bailout proportion was higher in PICCOLETO than in the BELLO study, and this might, especially with the lack of geographical match in PICCOLETO, have contributed to the diverging results. Nonetheless, a subgroup analysis showed, consistent with the findings from PEPCAD I [37], that bailout implantation in the BELLO study was associated with an increase in LLL of $0.02 \mathrm{~mm}$ in the DEB-only group compared to $0.37 \mathrm{~mm}$ in the DEB + BMS group. A recent long-term follow-up of the BELLO study showed that the trend towards superior clinical outcome in the DEB vs. DES group persisted at 24 months [51].

The Valentines II trial was a Web-based observational study with 38 investigators from 16 different countries investigating outcomes following implantation of the DIOR II DEB [10]. Low bailout and MACE rates were reported and no vessel thrombosis occurred after 7.5 months of follow-up. In a subgroup analysis, MACE tended to be higher in patients with diabetes. Angiographic follow-up was not mandatory, and only 35 out of the 102 patients underwent angiographic follow-up, potentially underestimating asymptomatic restenosis.

Kleber et al. retrospectively identified 56 patients with de novo lesions treated with a DEB-only strategy [52]. They found that local paclitaxel induced late lumen enlargement following DEB treatment measured by significantly increased minimal lumen diameter in-lesion after 4 months. Positive vessel remodelling induced by paclitaxel or perhaps plaque regression and vascular healing were speculated to be possible explanations. Importantly, the included patients were selected following successful predilatation with no major dissections or recoil, and per definition without any bailout BMS, thus favoring toward better results than might be expected in unselected populations.

In another retrospective study, Her et al. compared the SeQuent Please DEB with POBA [53]. As expected, SeQuent Please DEB was superior to POBA. In accordance with the study by Kleber et al. [52], 9 months angiographic follow-up showed positive remodelling, i.e., negative LLL in 35 out of 49 DEB-treated patients, perhaps because of a high plaque burden, as also seen in the study by Kleber et al. showing that most lumen 
enlargement happens in areas with high plaque burden [52].

Shin et al. used a fractional flow reserve-guided approach to treat with either DEB or DES [54]. Following successful POBA treatment of a de novo lesion, the fractional flow reserve was measured and if favorable $(>0.85)$ a DEB was applied, otherwise a DES was implanted. Sixty-six patients were included, 44 received a DEB and 22 a DES. No clinical events were reported after 12 months. Angiographic follow-up after 9 months showed a sustained luminal gain in the DEB group, while lumen decreased in the DES group. However, owing to larger acute luminal gain in the DES group following implantation, the net gain was still better in the DES group after 9 months. This reflects the problem of using LLL as an outcome measure when comparing a stent and a balloon, which will be discussed later. Furthermore, by design and use of fractional flow reserve to guide the treatment arm, DES implantation is most likely associated with more complex lesions, thereby complicating the comparison between groups. The study focused on rather large vessels with a reference diameter between 2.5 and $3.5 \mathrm{~mm}$ [54]. To gain insight into possible explanations for the observed positive remodelling, Ann et al. performed a serial IVUS and fractional flow reserve study [55]. Twenty-seven patients were treated with a SeQuent Please DEB, and after 9 months the luminal gain persisted with a low LLL of 0.02. Intravascular ultrasound virtual histology analysis showed that plaque composition was unchanged but that the amount of atheroma volume decreased significantly, and that mean lumen area increased after 9 months. Four thin-cap fibroartheromas converted to thick-cap atheromas, suggesting that plaque stabilization may be promoted with DEBs [55].
In summary, a DEB-only strategy proves efficient with results comparable to DES in a mixed clinical patient population with lesions in coronary vessels less than $2.5 \mathrm{~mm}$. Only two randomized controlled trials comparing DEB against DES exist, which report on very heterogeneous outcomes, and the majority of studies are real-world observational registries. Bailout rate ranges from 3\% to $36 \%$ and bailout seems to result in a worse outcome. Careful attention to avoid geographical mismatch as well as performing thorough predilatation before $\mathrm{DEB}$ treatment trends toward a better outcome.

\section{Drug-Eluting Balloons in Specific Clinical Scenarios}

In the following, studies of DEBs used in more specific clinical scenarios are presented. These studies are summarized in Table 3.

\section{Drug-Eluting Balloons in Bifurcation Lesions}

Bifurcation lesions account for 15-20\% of all lesions treated by PCI [56]. It offers a challenge for clinicians, and despite the use of DESs, treating bifurcations remains hampered by technical difficulties and suboptimal long-term results, especially with regard to the side branch (SB) [57]. Currently the preferred approach is stenting of the main branch (MB) with a DES and only provisional stenting of the SB [58].

The Drug Eluting Balloon in BIfurcation UTrect (DEBIUT) registry was the first registry to report on outcomes following use of DEBs in bifurcation lesions [59]. A small 20-patient registry was set up to explore the efficacy and safety of DEB use in bifurcations. Following predilatation of both $\mathrm{MB}$ and $\mathrm{SB}$, both vessels were treated with the DIOR I balloon catheter and a BMS was deployed in the MB. A short 4-month clinical follow-up revealed no incidences of MACE or ST. 
The Paclitaxel Eluting PTCA Balloon in Coronary Artery Disease (PEPCAD V) trial was another pilot study using a similar approach, and a SeQuent Please DEB was used for treatment of $\mathrm{MB}$ and $\mathrm{SB}$ and a BMS was deployed in MB [60]. The angiographic results were described as DES-like by the authors. Two late stent thromboses occurred, leading to a recommendation of 12 months of DAPT treatment in bifurcation lesions treated with DEB/BMS, instead of the 3 months used in the study.

Sgueglia et al. assessed the feasibility of "kissing" second-generation DEBs in a small study with 14 patients with a contraindication for DAPT [61]. The rationale was based on the assumption that second-generation DEBs have better mechanical properties than first-generation DEBs. The strategy was BMS implantation in MB followed by "kissing" DEB treatment in MB and SB. Four different DEBs were used (SeQuent Please, IN.PACT Falcon, DIOR II, Pantera Lux), with 100\% procedural success achieved and no MACE reported after an average of 8 months. The study laid the ground for an ongoing prospective registry of the kissing DEB technique (KISSING DEBBIE study, ClinicalTrials.gov NCT01009996).

The DEBIUT randomized trial sought to expand on the results from the DEBIUT registry [59], and investigated the use of predilatation with a DIOR-I DEB in the MB and SB followed by a BMS in the MB vs. BMS treatment of the MB vs. Taxus DES treatment of the MB [62]. In all cases, predilatation with a regular balloon was performed before intervention in both $\mathrm{MB}$ and SB. DIOR-I DEB failed to show superiority in angiographic outcomes compared to BMS, showed clearly worse outcome as compared to DES, and thereby was unable to confirm the promising results from the observational DEBUIT registry [59].
Schulz et al. were the first to investigate a DEB-only strategy in de novo bifurcation lesions without additional stenting of the SB or MB [63]. A SeQuent Please DEB or IN.PACT Falcon DEB was used for treatment of 38 patients. Five lesions required a bailout BMS in the SB. After 4 months of follow-up, the proportion of patients with a MACE was $7.7 \%$ all due to TLR, suggesting that DEB treatment was a relatively safe therapy. However, the fact that the DEB-only strategy required an acceptable angiographic result after predilatation, as well as the short period of follow-up, might limit the generalizability of these results.

The BABILON (Paclitaxel-Coated Balloon in Bifurcated Lesions) trial compared a provisional T-stenting technique for coronary bifurcation lesions with predilatation of both $\mathrm{SB}$ and $\mathrm{MB}$ with the SeQuent Please DEB followed by BMS implantation in the $\mathrm{MB}$ versus standard predilatation with plain balloons followed by XIENCE V DES in the MB [64]. Significantly more TLRs were observed in the DEB-treated group, mainly as a result of higher restenosis of the MB. The primary endpoint of LLL and secondary endpoint of MACE trended in favor of the DES group without reaching statistical significance. Overall, the authors concluded that there was no advantage of using DEB in the $\mathrm{SB}$ on the basis of current available data, and that XIENCE V DES in MB was at present a better strategy than BMS + DEB in MB.

The BIOLUX-I study was the first study to combine an everolimus DES with a paclitaxel DEB in the treatment of bifurcation lesions [65]. Following predilatation of $\mathrm{MB}$, the $\mathrm{SB}$ was treated with a Pantera Lux DEB, and subsequently, a Xience Prime/Xience V DES was implanted in the MB. The rationale was to maintain the simplicity of provisional stenting with the advantage of reducing restenosis of the 
SB. The primary endpoint showed a low LLL of $0.10 \mathrm{~mm}$ at 9 months. A core lab analysis showed that only 11 of the 35 lesions were "true" bifurcation lesions. However, low LLL persisted when this group was assessed separately. Clinical complication rates were low, and the authors concluded that the combination of an everolimus DES and paclitaxel DEB is a safe approach.

PEPCAD-BIF expanded on the initial result by Schulz et al. [63], being the second study using a DEB-only strategy in bifurcation lesions [58]. The lack of carina shift and the maintenance of natural flow distribution were among the potential benefits. Following successful predilatation of both $\mathrm{MB}$ and SB, 64 patients were randomly assigned to either SeQuent Please DEB treatment of $\mathrm{MB}$ and $\mathrm{SB}$ or POBA. Only five lesions required bailout stenting, all in the POBA group. The primary endpoint of in-lesion LLL was significantly lower in the DEB arm, and also low TLR rates were reported.

\section{Drug-Eluting Balloons in Chronic Total Occlusion or Diffuse Long Lesions}

Stent length is an independent predictor of in-stent restenosis and thrombosis [66]. Long, complex, and small vessel lesions, which are often hampered by several underlying comorbidities, create a challenge for the clinician.

Paclitaxel-Coated Balloon With Bare-Metal Stenting in Patients With Chronic Total Occlusions in Native Coronary Arteries (PEPCAD CTO) was the first study to investigate the combination of DEB and BMS in the treatment of complex chronic total occlusions [67]. The risks of restenosis and repeat revascularization after recanalization of chronic total occlusion are higher compared with de novo lesions. After successful recanalization of a chronic total occlusion in 48 patients, the native vessel segment was covered with BMS and finally treated with one or more DEBs. The group was compared with a historical comparable group treated with a Taxus DES. The BMS + DEB combination was associated with similar clinical results and a non-significantly higher in-stent LLL compared to the matched Taxus DES group.

In a pilot study, Basavarajaiah et al. adopted the same approach of a combined DEB + stent treatment of long diffuse lesions, but instead of BMS they used "limus" DES, assuming that a synergistic effect might be achieved with dual drug elution [68]. The intended strategy was to use DEB alone following predilatation, and in cases of a suboptimal result to implant a DES. Forty-six patients with lesions deemed high risk for restenosis, with $97 \%$ of lesions measuring more than $30 \mathrm{~mm}$, had one or more DES implanted following DEB treatment. In 20 patients the treated lesion was a de novo lesion (the rest being in-stent restenosis) and after 13 months a low MACE rate was reported in the de novo subgroup. There was one case of possible ST. It was not reported whether the thrombosis was in a de novo or an in-stent restenosis [68]. The same authors continued exploring a similar scenario where 63 patients with long diffuse lesions were treated with IN.PACT Falcon DEB or Pantera Lux DEB alone or in a planned combination with a DES, a "hybrid" approach [69]. By adopting this hybrid approach, the authors reported that overall stent length in long lesions may be reduced, thereby improving outcome. A matched cohort of 93 patients treated with DES alone in the same period was used for comparison. The average treated lesion length was similar between $\mathrm{DEB} \pm \mathrm{DES}$ and DES alone, but the total stented length differed significantly ( 29 vs. $50.2 \mathrm{~mm}$ ). A 2-year follow-up revealed similar 
rates of MACE and TLR [69]. The same author group presented another retrospective registry study of patients treated with the IN.PACT Falcon DEB [70]. The majority of lesions were diffuse ( $80 \%$ of lesions exceeding $20 \mathrm{~mm}$ ) and located in small vessels (70\% of vessels smaller than $2.5 \mathrm{~mm}$ ). In 79 patients with de novo lesions, $22 \%$ required bailout where a DES was implanted. A MACE rate of $16.5 \%$ was reported after 15 months and, given the complexity of the lesions, the authors found this rate acceptable. No ST occurred [70].

\section{Drug-Eluting Balloons in Acute Myocardial Infarction}

The need for repeat revascularization in ST elevation myocardial infarction (STEMI) is reduced with the introduction of DES, but death or myocardial infarction remains a problem. Factors like incomplete stent apposition and delayed tissue coverage are more frequently observed in STEMI patients than in (un)stable angina [71]. An acute myocardial infarction represents an inflammatory condition providing the opportunity for the local delivery of high concentrations of an antiproliferative drug by a DEB [12].

The DEB-AMI (Drug Eluting Balloon in Acute Myocardial Infarction) trial investigated the use of DEB in cases of acute myocardial infarction and compared BMS vs. DIOR II DEB + BMS vs. Taxus DES in a sample of 150 patients [50], see Table 3. The combination of DIOR II DEB + BMS failed to show superiority to BMS alone, and performed significantly worse than Taxus DES, angiographically as well as clinically. Optical coherence tomography was used to assess uncovered and malposed stent struts, and here DEB was better than DES. However, significantly fewer malpositions and uncovered stent struts were found in the BMS group. Thus, optical coherence tomography demonstrated that although there was no evidence of a clinical benefit with DEBs, there was a drug-induced effect on the vessel wall induced by the DEB. Of note, although mandatory according to protocol, only $60 \%$ of patients in the DEB group underwent predilatation with a regular balloon. Post hoc analyses on the DEB group showed that the 25 patients who underwent predilatation had an LLL of $0.49 \mathrm{~mm}$ compared to $0.85 \mathrm{~mm}$ in the 17 patients in the same group without predilatation.

Prompted by the promising DEB-only results from PEPCAD I and V, the investigators behind DEB-AMI established a fourth nonrandomized DEB-only arm [72]. The same inclusion criteria were applied, except that successful predilatation was mandatory before DEB treatment, presumably partly accounting for the low 10\% bailout rate. Angiographic outcomes favored DESs over DEB-only, but DEB-only was comparable to BMS alone and DEB followed by BMS. No ST occurred, suggesting DEB-only as a valid treatment in STEMI patients with a contraindication to DAPT.

These findings were supported by Ho et al. using the SeQuent Please DEB in the treatment of 89 patients presenting with STEMI [73]. Thrombus aspiration was performed in 56\% and predilatation in $100 \%$ of patients before DEB treatment, which yielded a low $4 \%$ bailout rate. A 1-month follow-up revealed four deaths, but all unrelated to the infarct-related artery, yielding zero TLR.

The PAPPA (Safety and feasibility of a PAclitaxel-eluting balloon angioplasty Primary Percutaneous coronary intervention in Amsterdam) study included 100 patients presenting with STEMI and investigated a DEB-only strategy with the Pantera Lux DEB [71]. Thrombus aspiration was recommended and predilatation was mandatory, but bailout 
was $40 \%$, markedly higher than in comparable studies. Despite the high bailout rate, good clinical outcomes were observed after 1 year. The high bailout proportion due to an excess rate of dissections is thought partly to be due to predilatation with a slightly oversized balloon. One early ST occurring $1 \mathrm{~h}$ after PCI was observed.

As a substudy of the previous presented SeQuent Please small vessel "PCB-only" Registry [35], Zuhdi et al. showed that among the 447 patients enrolled, 105 presented with acute coronary syndrome (STEMI or non-STEMI), and that bailout and clinical outcomes were comparable between the groups [44].

\section{Drug-Eluting Balloons in Patients with Diabetes}

Percutaneous coronary intervention in patients with diabetes is associated with more morbidity and mortality than in other populations, and a high risk of restenosis around 30\% after 6 months [74]. In general, coronary arteries in diabetes patients are more diffuse atherosclerotic, have more complex and longer lesions, and have a smaller caliber. In particular, reference diameter is found to be a major determinant of restenosis risk [74, 75]. In these circumstances, DEBs may be a favorable alternative to DESs.

The PEPCAD IV DM (Paclitaxel-Eluting Balloon Angioplasty and Cobalt-Chromium Stents Versus Conventional Angioplasty and Paclitaxel-Eluting Stents in the Treatment of Native Coronary Artery Stenoses of Diabetic Patients) trial enrolled 84 patients with diabetes to treatment with either the SeQuent Please DEB followed by BMS or the Taxus Liberté DES [76]. Geographical mismatch was taken into consideration, but predilatation, although recommended according to protocol, was only performed in $31.1 \%$ in the DEB group compared to $97.4 \%$ in the DES group. The minimal lumen diameter post PCI was $2.48 \mathrm{~mm}$ in the DEB group and $2.68 \mathrm{~mm}$ in the DES group, leading to a significant difference in the number of post PCI stenosis. However, after 9 months, no difference was found in the angiographic endpoint of in-stent/in-segment LLL as well as in clinical endpoints, suggesting DEB as a potential therapeutic alternative for de novo lesions in patients with diabetes mellitus.

In the observational DiabEtic Argentina Registry (DEAR) study, 91 patients with diabetes mellitus were treated with the DIOR II DEB followed by BMS implantation in $96 \%$ of patients at three centers [77]. This group was compared with outcome data from previous clinical studies conducted at the same centers in patients with diabetes mellitus treated with either a DES or BMS. Clinical outcomes with DIOR II DEB were significantly better than with a BMS, and trended toward a better outcome than those seen with a DES. No angiographic measures were performed. The nonrandomized study design, differences in baseline characteristics, and the fact that patient groups used for comparisons were treated years apart, given that technology and medical practice improve rapidly over time, are important limitations of the within-study comparison with BMS and DES.

\section{Drug-Eluting Balloons in Elderly Patients}

As part of a substudy from the SeQuent Please Small Vessel "PCB Only" Registry [35], Sinaga et al. were the first to investigate the use of DEBs in elderly patients [43]. In spite of an excess of comorbidities in the elderly (hypertension, renal impairment, atrial fibrillation, previous PCI) and more calcified lesions than in the younger age group, similar bailout rate $(7.3 \%$, age $<75 ; 6.7 \%$, age $\geq 75)$ and clinical outcome were observed in the two groups. 
The authors noticed that the results are comparable with the everolimus-eluting stent from the SPIRIT Small Vessel trial that reported a clinically indicated TLR of 5.1\% after 1 year [78]. The recommendation for DAPT treatment was 1 month, and most of the patients received DAPT for this period with a small proportion exceeding it [43]. As older people in general are more at risk of complications with prolonged DAPT treatment, this study showed a low $6.1 \%$ MACE after 9 months despite the shortened DAPT duration, highlighting the tempting aspects of DEB treatment and thereby avoidance of prolonged DAPT treatment in the elderly patients.

In short, while the planned combination of $\mathrm{DEB}+\mathrm{BMS}$ does not seem promising, especially in acute myocardial infarction, a DEB-only approach seems interesting in a broad range of different clinical scenarios. It has been suggested that the disappointing outcome in the scenario of acute myocardial infarction is explained by the different drug uptake in the acute ruptured plaque with high thrombus burden or a hampering effect by the presence of a BMS [12]. In bifurcation lesions, conflicting results were reported, with DES treatment of MB associated with a favorable outcome compared to DEB + BMS, whereas the DEB-only strategy in bifurcation indicated potentially promising results that warrant further investigation $[58,63]$. DEB in patients with diabetes, diffuse lesions, and elderly also reveals interesting results. Overall, the limited data makes it difficult to draw any firm conclusions about the use of DEB in these specific patient groups.

\section{STENT THROMBOSIS AND DUAL ANTIPLATELET THERAPY}

Data on the duration of DAPT treatment, early or late stent thrombosis, geographical mismatch, and duration of follow-up in the studies are found in Table $S 1$ the Appendix. Substudies are not included in this table, nor are studies where this information was insufficient or difficult to interpret. Most studies with a DEB-only strategy recommended 1-3 months of DAPT, 3-12 months in the case of additional BMS implantation, and 12 months in the case of DES. Most studies took geographical mismatch into consideration.

\section{DISCUSSION}

This review identified 52 studies of which 22 were randomized trials and 30 observational registries investigating either DEBs alone or in combination with a stent, mainly a BMS, in the treatment of coronary de novo lesions. Overall, the combination of DEB + BMS treatment did not seem to perform better than treatment with a DES, with most studies showing results in favor of DES or at best similar clinical or angiographic outcomes. A DEB-only approach on the other hand seems feasible and is generally associated with outcomes close to DES; however, some diverging evidence exists, best reflected by the two randomized controlled trials BELLO and PICCOLETO [48, 49]. Several factors might have contributed to these conflicting findings, including differences in bailout rate, predilatation, geographical mismatch, and the type of DEB used. For example, bailout proportion varied between $6 \%$ and $36 \%$, and in most cases bailout stenting is associated with a less favorable outcome [37, 46, 47, 49]; however, several prospective registries using SeQuent Please DEB did not find a difference between DEB treatment with or without BMS implantation $[35,39,41]$. Geographical mismatch between the DEB-treated area and BMS implantation 
seems partly to account for the observed differences, where especially the stent edges are sites of restenosis, and thus geographical mismatch should be avoided, and a BMS only implanted as a part of a bailout strategy $[21,24,28,37,49]$. The sequence of DEB treatment, before or after BMS implantation, was not found to significantly alter the outcome $[23,32,33]$. When BMS is implanted prior to DEB treatment a natural reference point for DEB dilatation exists (i.e., the BMS); to avoid geographical mismatch, extra caution should be taken when DEB dilatation precedes BMS implantation because the reference point for BMS implantation might be missing [33]. Predilatation of the target lesion is thought to create microdissections in the vessel wall, which in turn facilitates the uptake of drug and is therefore generally recommended prior to DEB implantation [50]. Predilatation in the PICCOLETO study was significantly higher in the DES arm, and might also have favored DES treatment in this study.

Most studies report on data from treatments performed on relatively small vessels with a reference diameter ranging from 2.48 to $3.30 \mathrm{~mm}$ in the planned DEB + BMS strategy and $1.95-2.80 \mathrm{~mm}$ in the DEB-only strategy, and with a follow-up of maximum 12 months except for five studies with at least 2 years of follow-up. As a potential benefit of using DEB was to avoid the late ST risk associated with DES implantation, the follow-up periods were generally too short to fully address this question. Furthermore, none of the studies included ST as a primary endpoint. Table S1 in the appendix illustrates that only the study by Żurakowski et al. [27] and PEPCAD I [37] found an excess of late ST in the DES group after a clinical follow-up of 9 and 6 months, respectively. However, Żurakowski et al. found more ST in the BMS + DEB arm in total as a result of more early ST in this group. In contrast, the INDICOR study found one late ST in the DEB + BMS arm and no ST in the DES arm [33]. Generally, the very few ST events in these studies yield potentially imprecise risk estimates. In many of the studies, stent thromboses, both early and late, were found to be associated with early cessation of DAPT treatment. In general, no conclusion can be drawn about the hypothesis of increased late ST associated with DES implantation from the available body of evidence.

Another key point related to the hypothesis of preventing ST is the need for prolonged DAPT when using DESs as compared to DEBs. Depending on the clinical setting, e.g., stable coronary artery disease or non-STEMI/ STEMI in patients undergoing PCI treatment, current guidelines recommend DAPT treatment for at least 6 and 12 months, respectively, assuming no contraindications to DAPT treatment [11]. With DEB and even $\mathrm{DEB}+\mathrm{BMS}$ treatment, the duration of DAPT treatment needed is thought to be shorter, thereby limiting bleeding risk. The included studies were not designed to investigate the impact of different duration of DAPT treatment on outcomes. Five studies differed in regard to duration of DAPT treatment with a short period of 1-3 month DAPT treatment in the DEB ( \pm BMS) arm compared to 12 months in the DES arm. Table S1 in the Appendix demonstrates no particular difference with regard to early or late vessel/stent thrombosis among these groups. Other endpoints such as clinical outcomes and bleeding risk should be considered. In general, studies using a DEB-only strategy show minimal risk of vessel thrombosis with only 1 month of DAPT. However, when DEBs are used in combination with a BMS the 
risk increases. Although few studies have found 3 months of DAPT sufficient with additional BMS implantation [38, 77], there is no current consensus about duration of DAPT, and other studies recommend 12 months of DAPT in case of BMS implantation [10, 27, 33].

Most of the studies compared the paclitaxel DEB to a paclitaxel DES in order to compare treatment devices using the same drug. This might be misleading as the sirolimus-eluting DES was shown to perform better than paclitaxel-eluting DES [7, 34]. Furthermore, newer-generation limus DES (everolimus and zotarolimus) perform even better than sirolimus DES [79]. Thus, by using the best DES on the market, even better DES results would be expected, and the potential benefit of treatment with a DEB might diminish. While different drugs exist for DES, paclitaxel for now seems the preferred drug and is to date the only one used for DEB in the treatment of human coronary arteries [17]. Also, the future impact of using DEBs with drugs other than paclitaxel remains to be investigated $[19,20]$.

\section{CONCLUSIONS AND FUTURE PERSPECTIVES}

The main indication for the use of DEB in the treatment of de novo coronary lesions seems to be small vessel disease, and especially in patients with high bleeding risk where a shorter time for DAPT treatment is favorable. A DEB-only strategy in bifurcations and in very high-risk patients, e.g., STEMI patients, also reveals promising results, especially if a low bailout rate is achieved. In case of DEB treatment the following is recommended: thorough predilatation before DEB treatment, to use a DEB-only strategy and only implant a BMS as part of a bailout strategy, and in case of need for bailout BMS implantation it is advised to use a shorter BMS and implant within the DEB-treated area to avoid geographical mismatch. In cases of doubt regarding geographical mismatch, post DEB treatment should be performed to make sure that the stent edges are fully covered with the drug.

The available body of evidence does not suggest that a DEB ( \pm BMS) treatment strategy is superior to DESs with respect to preventing associated early or late ST, but further studies with longer follow-up are warranted to assess the optimal DAPT duration across various populations. Nonetheless, 3 months of DAPT treatment in the case of DEB $( \pm \mathrm{BMS})$ implantation seems safe in an average risk population.

No class effect exists among the different paclitaxel DEBs, and DEBs with alternative drugs might reveal even more promising results, but such studies should be compared with the contemporary gold standard of DESs. Finally, most studies have investigated the use of DEBs in small vessels. Studies investigating the use of DEBs in large coronary vessels are warranted.

\section{ACKNOWLEDGMENTS}

No funding or sponsorship was received for this study or for the publication of this article. All named authors meet the International Committee of Medical Journal Editors (ICMJE) criteria for authorship for this manuscript, take responsibility for the integrity of the work as a whole, and have given final approval to the version to be published.

Disclosures. Svend Eggert Jensen has received an unrestricted research grant from Aachen Resonance. Rasmus Kapalu Broge Richelsen and Thure Filskov Overvad declare no conflict of interests. 
Compliance with Ethics Guidelines. This article is based on previously conducted studies and does not involve any new studies of human or animal subjects performed by any of the authors.

Open Access. This article is distributed under the terms of the Creative Commons Attribution-NonCommercial 4.0 International License (http://creativecommons.org/licenses/ by-nc/4.0/), which permits any noncommercial use, distribution, and reproduction in any medium, provided you give appropriate credit to the original author(s) and the source, provide a link to the Creative Commons license, and indicate if changes were made.

\section{REFERENCES}

1. Fischman DL, Leon MB, Baim DS, et al. A randomized comparison of coronary-stent placement and balloon angioplasty in the treatment of coronary artery disease. N Engl J Med. 1994;331:496-501.

2. Serruys PW, de Jaegere P, Kiemeneij F, et al. A comparison of balloon-expandable-stent implantation with balloon angioplasty in patients with coronary artery disease. $\mathrm{N}$ Engl J Med. 1994;331:489-95.

3. Gruchalla KJA, Nawarskas JJ. The paclitaxel-eluting stent in percutaneous coronary intervention: part I: background and clinical comparison to bare metal stents. Cardiol Rev. 2006;14:88-98.

4. Navarese EP, Austin D, Gurbel PA, et al. Drug-coated balloons in treatment of in-stent restenosis: a meta-analysis of randomised controlled trials. Clin Res Cardiol. 2013;102:279-87.

5. Eisenberg MJ, Konnyu KJ. Review of randomized clinical trials of drug-eluting stents for the prevention of in-stent restenosis. Am J Cardiol. 2006;98:375-82.

6. Bavry AA, Kumbhani DJ, Helton TJ, Borek PP, Mood GR, Bhatt DL. Late thrombosis of drug-eluting stents: a meta-analysis of randomized clinical trials. Am J Med. 2006;119:1056-61.
7. Stettler C, Wandel S, Allemann S, et al. Outcomes associated with drug-eluting and bare-metal stents: a collaborative network meta-analysis. Lancet. 2007;370:937-48.

8. Hassan AKM, Bergheanu SC, Stijnen T, et al. Late stent malapposition risk is higher after drug-eluting stent compared with bare-metal stent implantation and associates with late stent thrombosis. Eur Heart J. 2010;31:1172-80.

9. Chang M, Park DW. Optimal duration of dual antiplatelet therapy after implantation of drug-eluting stents: shorter or longer? Cardiol Ther. 2014;3:1-12.

10. Waksman R, Serra A, Loh JP, et al. Drug-coated balloons for de novo coronary lesions: results from the Valentines II trial. EuroIntervention. 2013;9:613-9.

11. Kolh P, Windecker S, Alfonso F, et al. 2014 ESC/ EACTS guidelines on myocardial revascularization: the Task Force on Myocardial Revascularization of the European Society of Cardiology (ESC) and the European Association for Cardio-Thoracic Surgery (EACTS). Developed with the special contribution of the European Association of Percutaneous Cardiovascular Interventions (EAPCI). Eur J Cardiothorac Surg. 2014;46:517-92.

12. Loh JP, Waksman R. Paclitaxel drug-coated balloons: a review of current status and emerging applications in native coronary artery de novo lesions. JACC Cardiovasc Interv. 2012;5:1001-12.

13. Hwang CW, Wu D, Edelman ER. Physiological transport forces govern drug distribution for stent-based delivery. Circulation. 2001;104:600-5.

14. Wöhrle J. Drug-coated balloons for coronary and peripheral interventional procedures. Curr Cardiol Rep. 2012;14:635-41.

15. Scheller B, Speck U, Abramjuk C, Bernhardt U, Böhm M, Nickenig G. Paclitaxel balloon coating, a novel method for prevention and therapy of restenosis. Circulation. 2004;110:810-4.

16. Kaule S, Minrath I, Stein F, Kragl U, Schmidt W, Schmitz K-P, et al. Correlating coating characteristics with the performance of drug-coated balloons-a comparative in vitro investigation of own established hydrogel- and ionic liquid-based coating matrices. PLoS One. 2015;10:e0116080.

17. Speck U, Scheller B, Hamm B. Drug-coated balloons for restenosis prophylaxis. Fortschr Röntgenstr. 2014;186:348-58. 
18. Bondesson P, Lagerqvist B, James SK, Olivecrona GK, Venetsanos D, Harnek J. Comparison of two drug-eluting balloons: a report from the SCAAR registry. EuroIntervention. 2012;8:444-9.

19. Granada JF, Milewski K, Zhao H, et al. Vascular response to zotarolimus-coated balloons in injured superficial femoral arteries of the familial hypercholesterolemic swine. Circ Cardiovasc Interv. 2011;4:447-55.

20. Schmehl J, von der Ruhr J, Dobratz M, et al. Balloon coating with rapamycin using an on-site coating device. Cardiovasc Intervent Radiol. 2013;36:756-63.

21. Herdeg C, Göhring-Frischholz K, Haase KK, et al. Catheter-based delivery of fluid paclitaxel for prevention of restenosis in native coronary artery lesions after stent implantation. Circ Cardiovasc Interv. 2009;2:294-301.

22. Clever YP, Cremers B, Speck U, Dietz U, Böhm M, Scheller B. Influence of a paclitaxel coated balloon in combination with a bare metal stent on restenosis and endothelial function: comparison with a drug eluting stent and a bare metal stent. Catheter Cardiovasc Interv. 2014;84:323-31.

23. Burzotta F, Brancati MF, Trani C, et al. Impact of drug-eluting balloon (pre- or post-) dilation on neointima formation in de novo lesions treated by bare-metal stent: the IN-PACT CORO trial. Heart Vessels. 2016;31:677-86.

24. Wohrle J, Birkemeyer R, Markovic S, et al. Prospective randomised trial evaluating a paclitaxel-coated balloon in patients treated with endothelial progenitor cell capturing stents for de novo coronary artery disease. Heart. 2011;97:1338-42.

25. Seeger J, Markovic S, Birkemeyer $\mathrm{R}$, et al. Paclitaxel-coated balloon plus bare-metal stent for de-novo coronary artery disease. Coron Artery Dis. 2016;27:84-8.

26. Jim MH, Fung RCY, Yiu KH, Ng AKY, Siu CW, Fan KYY. Combined paclitaxel-eluting balloon and Genous cobalt-chromium alloy stent utilization in de novo coronary stenoses (PEGASUS). J Interv Cardiol. 2013;26:556-60.

27. Żurakowski A, Buszman PP, Milewski KP, et al. Stenting and adjunctive delivery of paclitaxel via balloon coating versus durable polymeric matrix for de novo coronary lesions: clinical and angiographic results from the prospective randomized trial. J Interv Cardiol. 2015;28:348-57.

28. Poerner TC, Otto S, Gassdorf J, et al. Stent coverage and neointimal proliferation in bare metal stents postdilated with a paclitaxel-eluting balloon versus everolimus-eluting stents: prospective randomized study using optical coherence tomography at 6-month follow-up. Circ Cardiovasc Interv. 2014;7:760-7.

29. Otto S, Gassdorf J, Nitsche K, et al. Time course of vascular response after an a priori strategy of bare metal stent implantation post-dilated with a paclitaxel-coated balloon: implementation of a three dimensional analysis algorithm with optical coherence tomography. Cardiol J. 2016. doi:10. 5603/CJ.a2016.0018.

30. Fischer D, Scheller B, Schäfer A, et al. Paclitaxcel-coated balloon plus bare metal stent vs. sirolimus-eluting stent in de novo lesions: an IVUS study. EuroIntervention. 2012;8:450-5.

31. Liistro F, Porto I, Angioli P, et al. Elutax paclitaxel-eluting balloon followed by bare-metal stent compared with Xience V drug-eluting stent in the treatment of de novo coronary stenosis: a randomized trial. Am Heart J. 2013;166:920-6.

32. Gutiérrez-Chico JL, van Geuns RJ, Koch KT, et al. Paclitaxel-coated balloon in combination with bare metal stent for treatment of de novo coronary lesions: an optical coherence tomography first-in-human randomised trial, balloon first vs. stent first. EuroIntervention. 2011;7:711-22.

33. Kaul U, Unverdorben M, Degenhardt R, et al. The paclitaxel-eluting PTCA-balloon in combination with a cobalt-chromium stent in two different sequences to treat de novo coronary artery lesions: an angiographic follow up study. Indian Heart J. 2013;65:510-7.

34. Zhang X, Xie J, Li G, Chen Q, Xu B. Head-to-head comparison of sirolimus-eluting stents versus paclitaxel-eluting stents in patients undergoing percutaneous coronary intervention: a meta-analysis of 76 studies. PLoS One. 2014;9:e97934.

35. Zeymer U, Waliszewski $M$, Spiecker $M$, et al. Prospective "real world" registry for the use of the "PCB only" strategy in small vessel de novo lesions. Heart. 2014;100:311-6.

36. Mauri L, Orav EJ, Kuntz RE. Late loss in lumen diameter and binary restenosis for drug-eluting stent comparison. Circulation. 2005;111:3435-42.

37. Unverdorben $M$, Kleber FX, Heuer $H$, et al. Treatment of small coronary arteries with a paclitaxel-coated balloon catheter. Clin Res Cardiol. 2010;99:165-74.

38. Unverdorben $\mathrm{M}$, Kleber FX, Heuer $\mathrm{H}$, et al. Treatment of small coronary arteries with a paclitaxel-coated balloon catheter in the PEPCAD 
I study: are lesions clinically stable from 12 to 36 months? EuroIntervention. 2013;9:620-8.

39. Wöhrle J, Zadura M, Möbius-Winkler S, et al. SeQuentPlease World Wide Registry: clinical results of SeQuent please paclitaxel-coated balloon angioplasty in a large-scale, prospective registry study. J Am Coll Cardiol. 2012;60:1733-8.

40. Calé R, Sousa PJ, Pereira E, et al. One-year clinical outcomes of percutaneous treatment with drug-eluting balloons: results from a multicenter registry. Rev Port Cardiol. 2013;32:361-9.

41. Benezet J, Gutiérrez-Barrios A, Agarrado A, et al. Paclitaxel-coated balloon angioplasty for de novo coronary lesions: a long-term follow-up study. Minerva Cardioangiol. 2016;64:15-22.

42. Uhlemann M, Möbius-Winkler S, Adam J, et al. The Leipzig prospective drug-eluting balloon-registryoutcome of 484 consecutive patients treated for coronary in-stent restenosis and de novo lesions using paclitaxel-coated balloons. Circ J. 2016;80:379-86.

43. Sinaga DA, Ho HH, Zeymer U, et al. Drug coated balloon angioplasty in elderly patients with small vessel coronary disease. Ther Adv Cardiovasc Dis. 2015;9:389-96.

44. Mahmood Zuhdi AS, Zeymer U, Waliszewski M, et al. The use of paclitaxel coated balloon (PCB) in acute coronary syndrome of small vessel de novo lesions: an analysis of a prospective "real world" registry. Springerplus. 2016;5:373.

45. Ong PJL, Zeymer U, Waliszewski M, Tan J, Ho HH. Differences in clinical and angiographic profiles between Asian and Western patients with coronary artery disease: insights from the prospective "real world" paclitaxel-coated balloon registry. Int J Cardiol. 2014;175:199-200.

46. Toelg R, Merkely B, Erglis A, et al. Coronary artery treatment with paclitaxel-coated balloon using a BTHC excipient: clinical results of the international real-world DELUX registry. EuroIntervention. 2014;10:591-9.

47. Vaquerizo B, Miranda-Guardiola F, Fernández E, et al. Treatment of small vessel disease with the paclitaxel drug-eluting balloon: 6-month angiographic and 1-year clinical outcomes of the Spanish multicenter registry. J Interv Cardiol. 2015;28:430-8.

48. Cortese B, Micheli A, Picchi A, et al. Paclitaxel-coated balloon versus drug-eluting stent during PCI of small coronary vessels, a prospective randomised clinical trial. The PICCOLETO study. Heart. 2010;96:1291-6.

49. Latib A, Colombo A, Castriota F, et al. A randomized multicenter study comparing a paclitaxel drug-eluting balloon with a paclitaxel-eluting stent in small coronary vessels: the BELLO (balloon elution and late loss optimization) study. J Am Coll Cardiol. 2012;60:2473-80.

50. Belkacemi A, Agostoni P, Nathoe HM, et al. First results of the DEB-AMI (drug eluting balloon in acute ST-segment elevation myocardial infarction) trial: a multicenter randomized comparison of drug-eluting balloon plus bare-metal stent versus bare-metal stent versus drug-eluting stent in primary primary percutaneous coronary intervention with 6-month angiographic, intravascular, functional, and clinical outcomes. J Am Coll Cardiol. 2012;59:2327-37.

51. Naganuma T, Latib A, Sgueglia GA, et al. A 2-year follow-up of a randomized multicenter study comparing a paclitaxel drug-eluting balloon with a paclitaxel-eluting stent in small coronary vessels the BELLO study. Int J Cardiol. 2015;184:17-21.

52. Kleber FX, Schulz A, Waliszewski M, et al. Local paclitaxel induces late lumen enlargement in coronary arteries after balloon angioplasty. Clin Res Cardiol. 2015;104:217-25.

53. Her AY, Ann SH, Singh GB, et al. Comparison of paclitaxel-coated balloon treatment and plain old balloon angioplasty for de novo coronary lesions. Yonsei Med J Yonsei Univ Coll Med. 2016;57:337-41.

54. Shin E-S, Ann SH, Balbir Singh G, Lim KH, Kleber FX, Koo B-K. Fractional flow reserve-guided paclitaxel-coated balloon treatment for de novo coronary lesions. Catheter Cardiovasc Interv. 2015. doi:10.1002/ccd.26257.

55. Ann SH, Singh GB, Lim KH, Koo BK, Shin ES. Anatomical and physiological changes after paclitaxel-coated balloon for atherosclerotic de novo coronary lesions: serial IVUS-VH and FFR study. PLoS One. 2016;11:e0147057.

56. Meier B, Gruentzig AR, King SB, et al. Risk of side branch occlusion during coronary angioplasty. Am J Cardiol. 1984;53:10-4.

57. Wilensky RL, Selzer F, Johnston J, et al. Relation of percutaneous coronary intervention of complex lesions to clinical outcomes (from the NHLBI Dynamic Registry). Am J Cardiol. 2002;90:216-21. 
58. Kleber FX, Rittger H, Ludwig J, et al. Drug eluting balloons as stand alone procedure for coronary bifurcational lesions: results of the randomized multicenter PEPCAD-BIF trial. Clin Res Cardiol. 2016;105:613-21.

59. Fanggiday JC, Stella PR, Guyomi SH, Doevendans PA. Safety and efficacy of drug-eluting balloons in percutaneous treatment of bifurcation lesions: the DEBIUT (Drug-Eluting Balloon in BIfurcaton UTrecht) registry. Catheter Cardiovasc Interv. 2008;71:629-35.

60. Mathey DG, Wendig I, Boxberger M, Bonaventura $\mathrm{K}$, Kleber FX. Treatment of bifurcation lesions with a drug-eluting balloon: the PEPCAD V (Paclitaxel Eluting PTCA Balloon in Coronary Artery Disease) trial. EuroIntervention. 2011;7(Suppl K):K61-5.

61. Sgueglia GA, Todaro D, Bisciglia A, Conte M, Stipo A, Pucci E. Kissing inflation is feasible with all second-generation drug-eluting balloons. Cardiovasc Revasc Med. 2011;12:280-5.

62. Stella PR, Belkacemi A, Dubois C, et al. A multicenter randomized comparison of drug-eluting balloon plus bare-metal stent versus bare-metal stent versus drug-eluting stent in bifurcation lesions treated with a single-stenting technique: six-month angiographic and 12-month clinical results of the drug-eluting balloon in bifurcations trial. Catheter Cardiovasc Interv. 2012;80:1138-46.

63. Schulz A, Hauschild T, Kleber FX. Treatment of coronary de novo bifurcation lesions with DCB only strategy. Clin Res Cardiol. 2014;103:451-6.

64. López Mínguez JR, Nogales Asensio JM, Doncel Vecino LJ, et al. A prospective randomised study of the paclitaxel-coated balloon catheter in bifurcated coronary lesions (BABILON trial): 24-month clinical and angiographic results. EuroIntervention. 2014;10:50-7.

65. Worthley S, Hendriks R, Worthley $M$, et al. Paclitaxel-eluting balloon and everolimus-eluting stent for provisional stenting of coronary bifurcations: 12-month results of the multicenter BIOLUX-I study. Cardiovasc Revasc Med. 2015;16:413-7.

66. Lee CW, Park D-W, Lee B-K, et al. Predictors of restenosis after placement of drug-eluting stents in one or more coronary arteries. Am J Cardiol. 2006;97:506-11.

67. Wöhrle J, Werner GS, Wohrle J, Werner GS. Paclitaxel-coated balloon with bare-metal stenting in patients with chronic total occlusions in native coronary arteries. Catheter Cardiovasc Interv. 2013;81:793-9.
68. Basavarajaiah S, Latib A, Hasegawa $\mathrm{T}$, et al. Assessment of efficacy and safety of combining "paclitaxel" eluting balloon and "limus" eluting stent in the same lesion. J Interv Cardiol. 2013;26:259-63.

69. Costopoulos C, Latib A, Naganuma T, et al. The role of drug-eluting balloons alone or in combination with drug-eluting stents in the treatment of de novo diffuse coronary disease. JACC Cardiovasc Interv. 2013;6:1153-9.

70. Basavarajaiah S, Latib A, Shannon J, et al. Drug-eluting balloon in the treatment of in-stent restenosis and diffuse coronary artery disease: real-world experience from our registry. J Interv Cardiol. 2014;27:348-55.

71. Vos NS, Dirksen MT, Vink MA, et al. Safety and feasibility of a PAclitaxel-eluting balloon angioplasty in Primary Percutaneous coronary intervention in Amsterdam (PAPPA): one-year clinical outcome of a pilot study. EuroIntervention. 2014;10:584-90.

72. Nijhoff F, Agostoni P, Belkacemi A, et al. Primary percutaneous coronary intervention by drug-eluting balloon angioplasty: the nonrandomized fourth arm of the DEB-AMI (drug-eluting balloon in ST-segment elevation myocardial infarction) trial. Catheter Cardiovasc Interv. 2015;86(Suppl 1):S34-44.

73. Ho HH, Tan J, Ooi YW, et al. Preliminary experience with drug-coated balloon angioplasty in primary percutaneous coronary intervention. World J Cardiol. 2015;7:311-4.

74. West NEJ, Ruygrok PN, Disco CMC, et al. Clinical and angiographic predictors of restenosis after stent deployment in diabetic patients. Circulation. 2004;109:867-73.

75. Jimenez-Navarro MF, Curiel E, Hernandez Garcia $\mathrm{JM}$, et al. Influence of diabetes mellitus on clinical outcome after percutaneous coronary revascularization. Rev Esp Cardiol. 2002;55:365-71.

76. Ali RM, Degenhardt R, Zambahari R, et al. Paclitaxel-eluting balloon angioplasty and cobalt-chromium stents versus conventional angioplasty and paclitaxel-eluting stents in the treatment of native coronary artery stenoses in patients with diabetes mellitus. EuroIntervention. 2011;7(3):K83-92.

77. Mieres J, Fernandez-Pereira C, Risau G, et al. One-year outcome of patients with diabetes mellitus after percutaneous coronary intervention with three different revascularization strategies: results from the Diabetic Argentina Registry (DEAR). Cardiovasc Revasc Med. 2012;13:265-71. 
78. Cannon LA, Simon DI, Kereiakes D, et al. The XIENCE nano everolimus eluting coronary stent system for the treatment of small coronary arteries: the SPIRIT Small Vessel trial. Catheter Cardiovasc Interv. 2012;80:546-53.
79. Piccolo R, Stefanini GG, Franzone A, et al. Safety and efficacy of resolute zotarolimus-eluting stents compared with everolimus-eluting stents: a meta-analysis. Circ Cardiovasc Interv. 2015;8: e002223. 